\title{
Synthesis of Fluvirucins and Their Aglycons, the Fluvirucinins
}

\author{
Mercedes Amat* \\ Núria Llor \\ Guillaume Guignard \\ Joan Bosch*
}

Laboratory of Organic Chemistry, Faculty of Pharmacy, and Institute of Biomedicine (IBUB), University of Barcelona, Av. Joan XXIII 27-31, 08028 Barcelona, Spain

amat@ub.edu

joanbosch@ub.edu

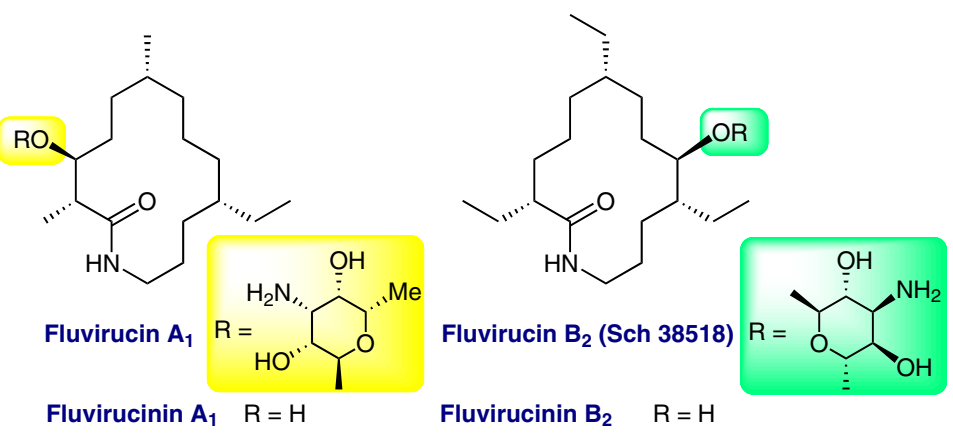

Received: 21.04 .2016

Accepted after revision: 29.04.2016

Published online: 23.06 .2016

DOI: 10.1055/s-0035-1561469; Art ID: ss-2016-z0272-sr

Abstract Fluvirucins are bioactive macrolactam glycosides isolated from actinomycetes. This review gives an overview of this family of natural products, covering isolation, biological activities, biosynthesis, and total synthesis. The synthesis of fluvirucins and their aglycons, the fluvirucinins, is presented, paying special attention to the synthetic strategy and stereochemical aspects.

Introduction

Isolation, Biological Activity, and Biosynthesis Synthetic Approaches

3.1 Closure of the 14-Membered Ring by Ring-Closing Metathesis

3.2 Closure of the 14-Membered Ring by Macrolactamization

3.3 Construction of the 14-Membered Ring by Aza-Claisen Ring Expansion

4 Conclusion

Key words macrolactams, synthetic strategy, ring-closing metathesis, macrolactamization, aza-Claisen rearrangement, stereoselectivity

\section{Introduction}

Fluvirucins are a family of naturally occurring glycosides structurally characterized by the presence of an amino sugar attached at the C-3 or C-9 position of a 14-membered macrocycle lactam aglycon. They also incorporate a methyl or ethyl substituent at C-2 [(S)-1-hydroxyethyl in fluvirucin $A_{2}$ ], C-6 (absent in some members), and C-10 of the core lactam nucleus. The amino sugar moiety can be 3amino-3,6-dideoxy- $\alpha$-L-talopyranose, e.g. in fluvirucins $A_{1}$ and $B_{1}$, or its 4-epimer (L-mycosamine), e.g. in fluvirucin $B_{2}$, or an $\mathrm{N}$-substituted derivative of either.

\section{Isolation, Biological Activity, and Biosyn- thesis}

The first member of the fluvirucin family (Sch 38516) was reported in 1990 by scientists at Schering-Plough, who obtained it by extraction from the fermentation broth of the actinomycete Actinomadura vulgaris. ${ }^{1}$ Its structure was established by X-ray crystallographic analysis. In the following years, the same group reported the isolation of seven other glycosides (Sch 38511-38513, Sch 38518, and their C-4' epimers) produced by various species of Actinomadura. ${ }^{2,3}$ (Figure 1). All these compounds were found to exhibit antifungal activity against various strains of Candida sp. and dermatophytes.

Almost simultaneously, scientists at Bristol-Myers Squibb described seven macrolactam glycosides, named fluvirucins $A_{1}, A_{2}$, and $B_{1}-B_{5}$, from several actinomycete strains. These fluvirucins possess inhibitory activity against the influenza A virus, ${ }^{4}$ which is partially retained in the corresponding fluvirucinins. ${ }^{4 b}$

Fluvirucin $\mathrm{B}_{2}$ also acts as an inhibitor of phosphatidylinositol-specific phospholipase C. ${ }^{5}$ The structures of some of these fluvirucins coincided with those previously reported by the Schering-Plough researchers.

More recently, researchers at Merck have reported the isolation of fluvirucin $\mathrm{B}_{0}{ }^{6}$ and two new $\mathrm{N}$-methyl derivatives of fluvirucin $\mathrm{A}_{1}{ }^{7}$ from the actinomycete Nonomuraea turkmerniaca, all of which show anthelmintic activity.

By ${ }^{13} \mathrm{C}$ feeding experiments, it was demonstrated that the aglycon moiety of fluvirucins is biosynthesized from acetate and propionate via a combination of polyketide and tricarboxylic acid mechanisms. ${ }^{4 b, 8}$ In this context, the identification and characterization of the putative polyketide 

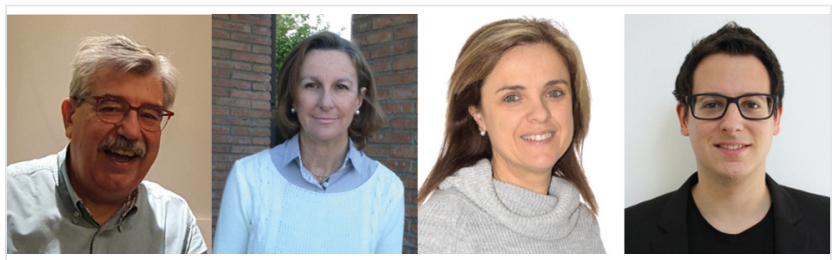

(from left to right)

Joan Bosch was born in Barcelona, Spain, in 1947. He graduated in Chemistry (1969) and completed his Ph.D. degree (1973) at the University of Barcelona, where he has been Professor of Organic Chemistry at the Faculty of Pharmacy since 1982. He was Vice-Dean (1983-1986) and Dean (1986-1992) of this Faculty, and Head of the Department of 'Pharmacology and Medicinal Chemistry' (1992-1998). His research is focused on the development of general methods and strategies for the synthesis of alkaloids, in particular indole- and piperidine-containing alkaloids. He has published more than 300 scientific papers and supervised $40 \mathrm{Ph}$.D. theses. He has been involved in many collaborative projects with chemical and pharmaceutical companies aimed at the synthesis of new therapeutic agents and the development of new synthetic routes for active pharmaceutical ingredients. He was awarded the 'Distinction for the Promotion of University Research' by the Government of Catalunya (2002) and the prize GEPRONAT for research in natural products chemistry by the Spanish Royal Society of Chemistry (2011). Since 2010 he has been the President of the Organic Chemistry division of the Spanish Royal Society of Chemistry.

Mercedes Amat was born in Castellón, Spain, in 1956. She graduated in Pharmacy at the University of Barcelona (1979), where she completed her Ph.D. (1984) under the supervision of Prof. Joan Bosch. After a postdoctoral stay as a Fulbright scholar at the University of Virginia with Prof. Richard J. Sundberg working on the total synthesis of natural products, she returned to the University of Barcelona to take up a permanent position as Associate Professor of Organic Chemistry at the Faculty of Pharmacy (1986), being promoted to the position of Full Professor in 1997. During the period 2005-2013 she was the Head of the Department of 'Pharmacology and Medicinal Chemistry'. Her research interests include the development of synthetic methodology for the enantioselective synthesis of nitrogen-containing compounds and its application to the total synthesis of alkaloids. She has published more than 130 scientific papers and supervised 20 doctoral theses and several postdoctoral researchers. In 2015, she was honored by the Spanish Royal Society of Chemistry with the Fèlix Serratosa medal, which recognizes significant and continuous contributions to organic chemistry. Núria Llor was born in Barcelona, Spain, in 1968. She graduated in Pharmacy in 1991 and obtained her Ph.D. in 1996 under the supervision of Professors Mercedes Amat and Joan Bosch at the University of Barcelona, where she currently holds a permanent position of 'Professor Agregat'. Her research is currently focused on the enantioselective synthesis of natural products using phenylglycinol-derived lactams as enantiomeric scaffolds.

Guillaume Guignard was born in Saint-Nazaire, France, in 1987. After receiving his B.Sc. (2009) and Master's (2011) degrees in Organic Chemistry from the University of Nantes, he joined the research group of Professors Amat and Bosch at the University of Barcelona, where he completed his Ph.D. in 2016 working on the synthesis of Haliclona alkaloids and fluvirucinin $\mathrm{B}_{1}$.

synthase genes associated with fluvirucin $\mathrm{B}_{1}$ aglycon biosynthesis in Actinomadura vulgaris has recently been reported. ${ }^{9}$

\section{Synthetic Approaches}

The synthesis of fluvirucins has been little explored. In fact, only one total enantioselective synthesis of a member of this group, fluvirucin $B_{1}$, has been reported to date. In contrast, fluvirucinins have received considerable attention from the synthetic standpoint, which has resulted in enantioselective syntheses of fluvirucinins $A_{1}, A_{2}, B_{0}, B_{1}$, and $B_{2-5}$, the latter being the aglycon common to fluvirucins $B_{2}, B_{3}$, $\mathrm{B}_{4}$, and $\mathrm{B}_{5}$.

Two key issues in the synthesis of fluvirucins and fluvirucinins are the closure of a 14-membered lactam ring and the control of the configuration of its stereocenters.

As outlined in Figure 2, three main strategies have been used for the construction of the macrocyclic ring: 1. olefin ring-closing metathesis reaction (bond formed $\mathrm{C}_{4}-\mathrm{C}_{5}, \mathrm{C}_{5}-\mathrm{C}_{6}$, $\mathrm{C}_{6}-\mathrm{C}_{7}$, or $\mathrm{C}_{8}-\mathrm{C}_{9}$ ); 2 . macrolactamization (bond formed N$\mathrm{C}_{1}$ ); and 3. amide-enolate-induced ring expansion via azaClaisen rearrangement of a 10-membered 1-acyl-2alkoxyvinyl-azacycle (bond formed $C_{2}-C_{3}$ ).

For the sake of clarity, the carbon numbering used in this review for the synthetic intermediates corresponds to that of the fluvirucinin system. In addition, to facilitate its visualization, the fluvirucinin ring skeleton has been drawn with the same orientation throughout the review, both in the $A$ and $B$ series.

\subsection{Closure of the 14-Membered Ring by Ring- Closing Metathesis}

\subsubsection{Hoveyda's Approach to Fluvirucinin $B_{1}$ and Flu- virucin $\mathrm{B}_{1}$}

The first synthesis of a fluvirucinin was reported by Hoveyda in $1995 .{ }^{10}$ Two relevant aspects of the synthesis are the use of a ring-closing metathesis (RCM) reaction to promote stereoselective macrocyclization from a conformationally mobile acyclic diene, and the use of macrocyclic stereocontrol to establish the remote stereochemistry at C-6 by catalytic hydrogenation. Thus, closure of the 14-membered ring was efficiently accomplished (bond formed $\mathrm{C}_{5}-$ $\mathrm{C}_{6}$ ) under smooth conditions, using the Schrock Mo catalyst, from amido diene $\mathbf{3}$, which was convergently prepared by coupling of acid $\mathbf{1}$ with amine $\mathbf{2}$ (Scheme 1 ). Catalytic hydrogenation of the resulting trisubstituted $Z$ olefin $\mathbf{4}$ stereoselectively installed the C-6 stereogenic center to afford, after deprotection, fluvirucinin $\mathrm{B}_{1}$, which was converted into the corresponding acetate. ${ }^{10,11}$

The required starting materials $\mathbf{1}$ and $\mathbf{2}\left(\mathrm{C}_{1}-\mathrm{C}_{5}\right.$ and $\mathrm{C}_{6}-\mathrm{N}$ fragments, respectively, of fluvirucinin $B_{1}$ ), which incorporate the $\mathrm{C}-2, \mathrm{C}-9$, and $\mathrm{C}-10$ stereogenic centers of fluvirucinin $B_{1}$, were prepared as outlined in Scheme 2. ${ }^{10,11}$ Acid $\mathbf{1}$, with the required $R$ configuration, was prepared from dihy- 


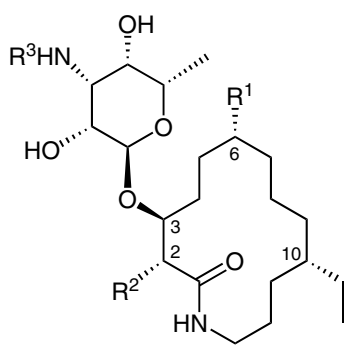

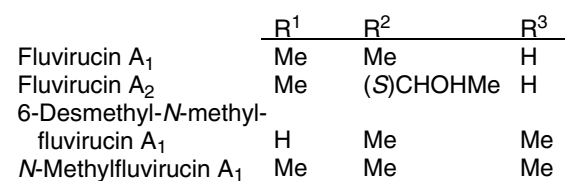

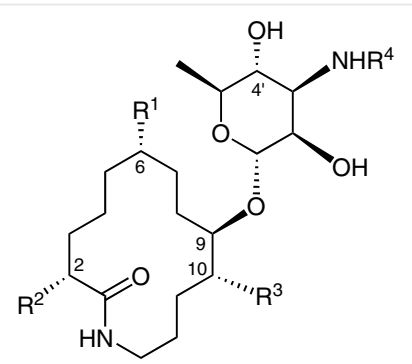

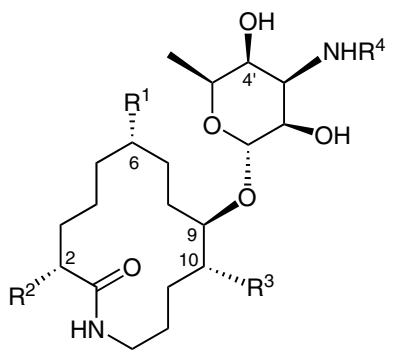

Sch 38511 Sch 38512

Sch 38513

Fluvirucin $\mathrm{B}_{2}$

Fluvirucin $\mathrm{B}_{4}$

\begin{tabular}{llll}
$\mathrm{R}^{1}$ & $\mathrm{R}^{2}$ & $\mathrm{R}^{3}$ & $\mathrm{R}^{4}$ \\
\hline $\mathrm{Me}$ & $\mathrm{Me}$ & $\mathrm{Me}$ & $\mathrm{H}$ \\
$\mathrm{Me}$ & $\mathrm{Et}$ & $\mathrm{Me}$ & $\mathrm{H}$ \\
$\mathrm{H}$ & $\mathrm{Et}$ & $\mathrm{Et}$ & $\mathrm{H}$ \\
$\mathrm{Me}$ & $\mathrm{Et}$ & $\mathrm{Et}$ & $\mathrm{H}$ \\
$\mathrm{Et}$ & $\mathrm{Et}$ & $\mathrm{Et}$ & $\mathrm{H}$ \\
$\mathrm{Et}$ & $\mathrm{Et}$ & $\mathrm{Et}$ & $\mathrm{CONH}\left(\mathrm{CH}_{2}\right)_{2} \mathrm{Ph}$
\end{tabular}

${ }^{a}$ Tentatively assigned
$4^{\prime}$-epi-Sch $38511^{a}$ $4^{-}-$epi-Sch $38512^{a}$

Fluvirucin $\mathrm{B}_{0}$

Fluvirucin $B_{1}$ (Sch 38516)

Fluvirucin $B_{3}$ (Sch 39185)

Fluvirucin $\mathrm{B}_{5}$

Figure 1 Structures of fluvirucins

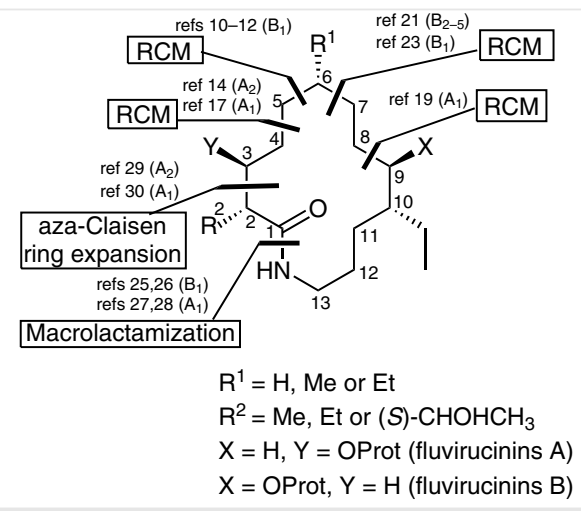

Figure 2 Closure of the 14-membered lactam ring

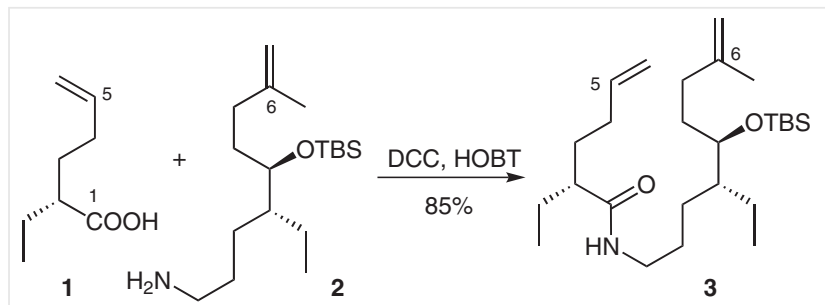

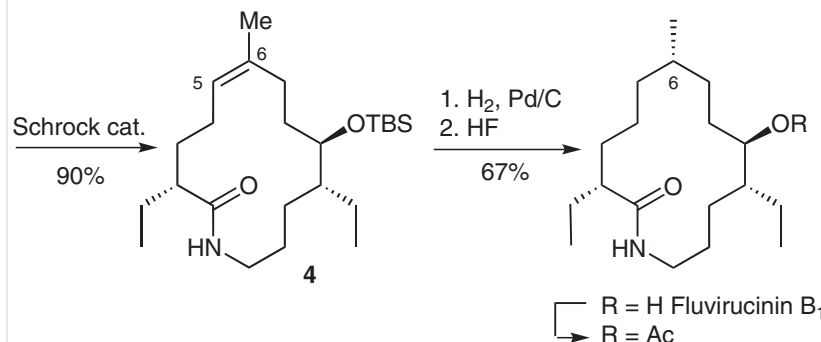

Scheme 1 Final steps of Hoveyda's synthesis of fluvirucinin $B_{1}$ drofuran $\mathbf{5}$ via a sequence of three metal-catalyzed steps. Enantioselective $\mathrm{Zr}$-catalyzed ethylmagnesation of $\mathbf{5}$ gave homoallylic alcohol $\mathbf{6}$, which was subjected to a tandem Tiand Ni-catalyzed hydrovinylation by hydromagnesation of the olefin, followed by in situ cross-coupling reaction of the resulting Grignard reagent $\mathbf{7}$ with vinyl bromide. Ru-catalyzed oxidation of the resulting alcohol $\mathbf{8}$ completed the synthesis of acid $\mathbf{1 .}$

In turn, homoallylic alcohol $\mathbf{9}$ was converted into enantiopure allylic alcohol $\mathbf{1 0}$ (>99\% ee) via kinetic Sharpless resolution of the corresponding racemate. Subsequent onepot double alkylation of the monosubstituted olefin moiety of 10, involving a diastereoselective $\mathrm{Zr}$-catalyzed ethylmagnesation, and in situ trapping of the resulting alkylmagnesium halide intermediate $\mathbf{1 1}$ with $\mathrm{N}$-tosylaziridine, afforded $12(\mathrm{dr}=97: 3)$. Final protection-deprotection steps led to amine $\mathbf{2}$ in 12\% overall yield for the six-step procedure.

The same strategy was employed for the synthesis of fluvirucin $B_{1}$ (Sch 38516), which incorporates a novel carbohydrate moiety identified for the first time in a natural product. However, all attempts to glycosylate the deprotected alcohol derived from $\mathbf{4}$ with a variety of carbohydrate derivatives failed, probably due to the low solubility of the macrocyclic alcohol in organic solvents.

This problem was circumvented using the more readily soluble alcohol resulting from deprotection of acyclic diene 3, which underwent stereoselective glycosylation with fluoroglycoside $\mathbf{1 3}$ to give $\mathbf{1 4}$ in excellent yield (Scheme 3). Subsequent RCM, followed by stereoselective hydrogenation of the resulting Z-unsaturated macrolactam 15 and deprotection of the sugar moiety, afforded fluvirucin $B_{1}$ (Sch 38516). ${ }^{11,12}$ This was the first, and to date the only, synthesis of a member of the fluvirucin family. 

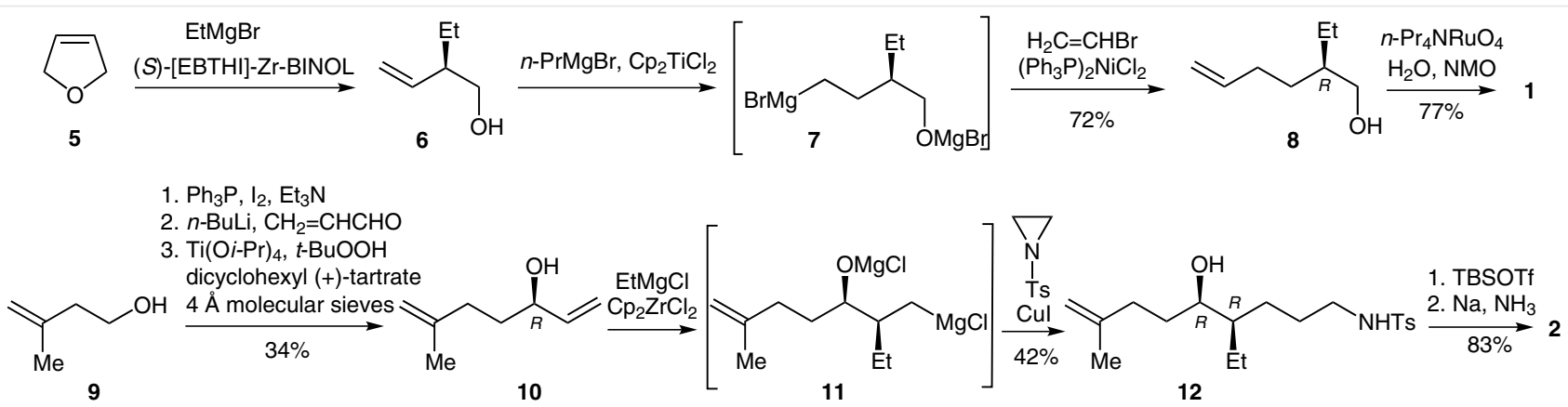

Scheme 2 Preparation of $C_{1}-C_{5}$ and $C_{6}-N$ fragments in Hoveyda's synthesis of fluvirucinin $B_{1}$

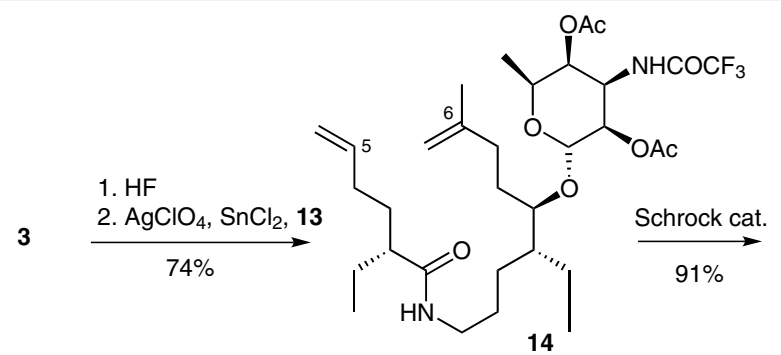

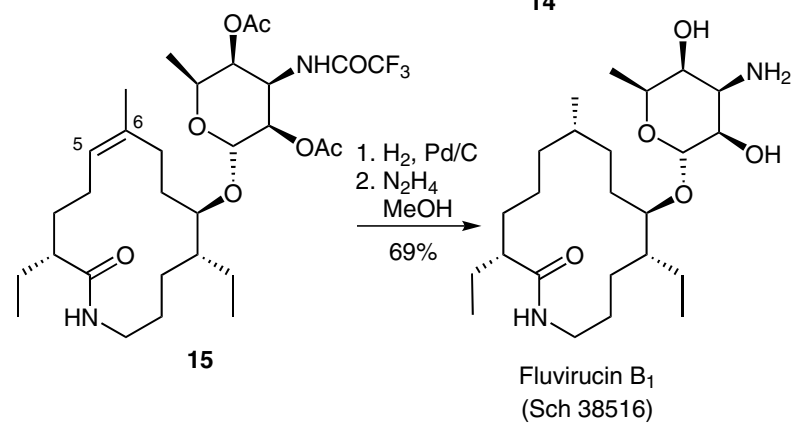

Scheme 3 Final steps of Hoveyda's synthesis of fluvirucin $B_{1}$ (Sch 38516)
The carbohydrate fragment $\mathbf{2 0}$ of fluvirucin $\mathrm{B}_{1}$ was prepared from ethyl sorbate (16) as illustrated in Scheme 4. Key steps of the synthesis are catalytic Sharpless asymmetric ( $80 \%$ ee) dihydroxylation of $\mathbf{1 6}$, which ensured the optical purity, diastereoselective dipolar [3+2] cycloaddition between $(R)$ - $\alpha$-methylbenzylamine-derived nitrone $\mathbf{1 8}$ and vinylene carbonate, and the removal of the protecting groups from the resulting cycloaddition product 19 by controlled acid hydrolysis and hydrogenolysis. The stereochemical identity of $\mathbf{2 0}$ was established through conversion into the corresponding $0,0, N$-triacetyl methyl glycoside, which proved identical to the material obtained from degradation of natural fluvirucin $B_{1}$.

To perform the crucial glycosylation reaction, 20 was protected as an 0,0 -diacetyl- $N$-trifluoroacetyl derivative and then activated as a fluoroglycoside 13 via acetoxyglycoside $\mathbf{2 1}$ and a thioglycoside. ${ }^{11-13}$

\subsubsection{Bracher's Approach to Fluvirucinin $\mathbf{B}_{\mathbf{0}}$}

In 2002, Bracher reported ${ }^{14}$ the enantioselective synthesis of 6-norfluvirucinin $B_{1}$ before it was known that this nor derivative was the aglycon of fluvirucin $B_{0}$. The closure of the macrolactam ring was also achieved by RCM reaction,

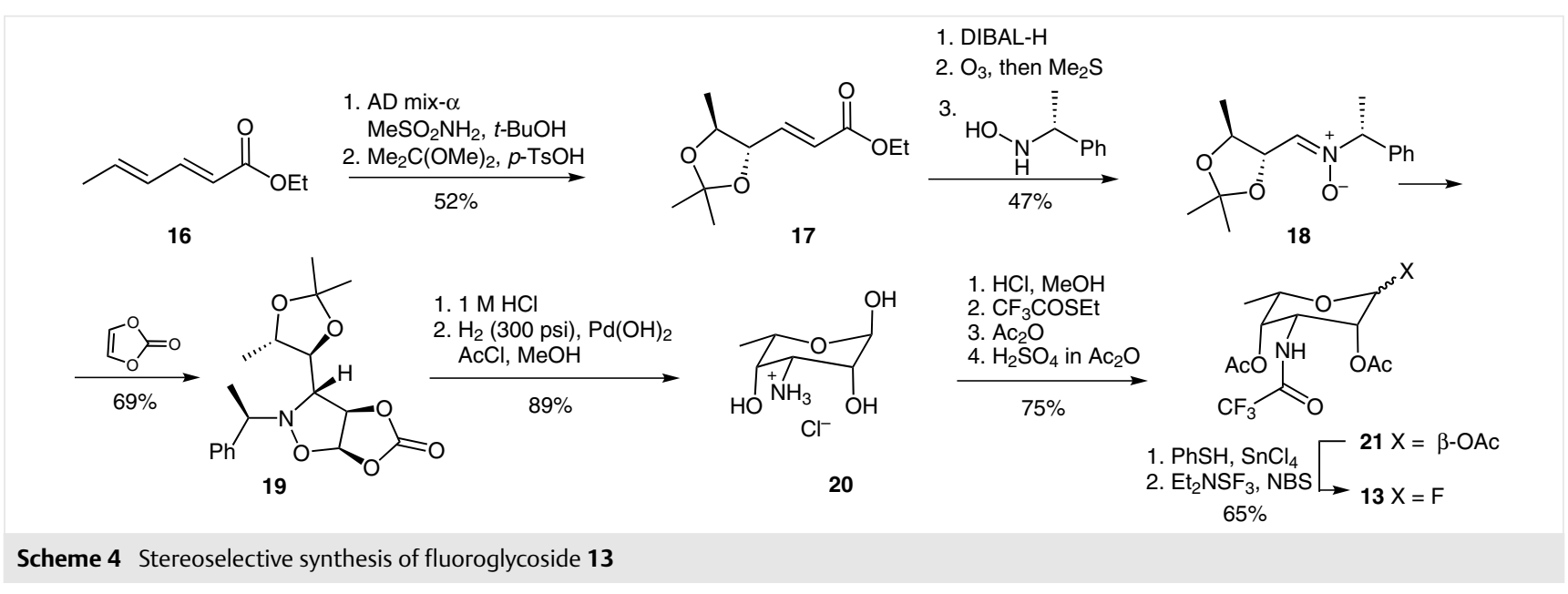


<smiles>C=CCCCC(OCc1ccccc1)C(CC)CCCNC(=O)[C@H](CC)CC=C</smiles>

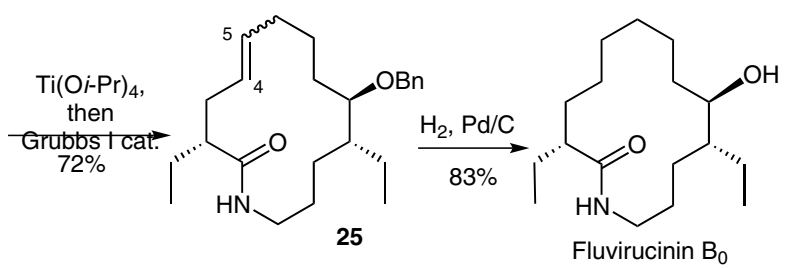

Scheme 5 Final steps of Bracher's synthesis of fluvirucinin $B_{0}$

although, in this case, involving the formation of the $\mathrm{C}_{4}-\mathrm{C}_{5}$ bond.

The required amido diene $\mathbf{2 4}$, which incorporates the three stereocenters of fluvirucinin $B_{0}$, was synthesized by coupling acid 22 with amine $23\left(\mathrm{C}_{1}-\mathrm{C}_{4}\right.$ and $\mathrm{C}_{5}-\mathrm{N}$ fragments of fluvirucinin $\mathrm{B}_{0}$ ). The RCM of $\mathbf{2 4}$ was satisfactorily performed with Grubbs' catalyst, in the presence of $\mathrm{Ti}(\mathrm{O} i-\mathrm{Pr})_{4}$ to avoid the formation of an unproductive Ru chelate with the $\gamma, \delta$-unsaturated amide. Subsequent catalytic hydrogenation of the resulting diene $\mathbf{2 5}$ led to fluvirucinin $\mathrm{B}_{0}$ (Scheme 5).
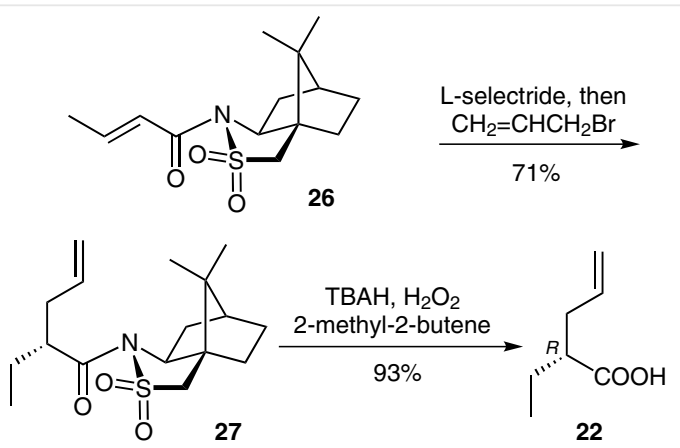

Scheme 6 Preparation of (R)-2-ethylpent-4-enoic acid
Enantiopure acid $\mathbf{2 2}$ was prepared in two steps from Oppolzer's $N$-crotyl-(+)-camphorsultam $\mathbf{2 6},{ }^{15}$ by conjugate hydride addition followed by trapping of the resulting enolate with allyl bromide and subsequent hydrolysis of $\mathrm{N}$ acylsultam $\mathbf{2 7}$ (Scheme 6).

In turn, amine $\mathbf{2 3}$ was obtained from epoxy alcohol $\mathbf{2 8 ,}$ which was accessible by Sharpless oxidation of the corresponding (E)-pentenol. ${ }^{16}$ After protection of the hydroxy group, regio- and stereoselective ring-opening reaction with an alkynyl alanate derived from $\mathbf{2 9}$ gave alcohol $\mathbf{3 0}$, which was converted into saturated epoxide 31. Regioselective opening of $\mathbf{3 1}$ with 3-butenylmagnesium bromide, followed by protection-deprotection steps and conversion of the primary alcohol function of $\mathbf{3 2}$ into a primary amino group, completed the synthesis of the amine half $\mathbf{2 3}$ (Scheme 7). ${ }^{14}$

\subsubsection{Radha Krishna's Approach to Fluvirucinin $A_{1}$}

In 2011, Radha Krishna reported ${ }^{17}$ an enantioselective synthesis of fluvirucinin $A_{1}$ involving the same $C_{4}-C_{5}$ bond disconnection. Closure of the macrocyclic ring was also achieved by RCM reaction, in this case from diene 35, which was prepared in nearly quantitative yield by amidation between carboxylic acid $\mathbf{3 3}$ and amine $\mathbf{3 4}\left(\mathrm{C}_{1}-\mathrm{C}_{4}\right.$ and $\mathrm{C}_{5}-\mathrm{N}$ fragments of fluvirucinin $A_{1}$ ). Hydrogenation of the resulting unsaturated macrolactam 36 ( $Z / E$ mixture) brought about both the reduction of the olefinic bond and the deprotection of the alcohol function to furnish fluvirucinin $\mathrm{A}_{1}$ (Scheme 8).

Both fragments, $\mathbf{3 3}$ and $\mathbf{3 4}$, were accessed from a common intermediate $\mathbf{3 8}$ derived from (S)-Roche ester $\mathbf{3 7}$, which provided the C-2 and C- 6 stereogenic centers of fluvirucinin $A_{1}$. Conversion of ester 37 into allylic alcohol $\mathbf{3 8}^{18}$ followed by Sharpless asymmetric epoxidation afforded epoxy alcohol 39, ${ }^{18 b}$ which was converted into allylic alcohol 40 by $\mathrm{Zn}$ reduction of the corresponding iodide. Subsequent protecting group interconversions and oxidation of the primary alcohol function afforded $O$-protected hydroxy acid 33 (Scheme 9).

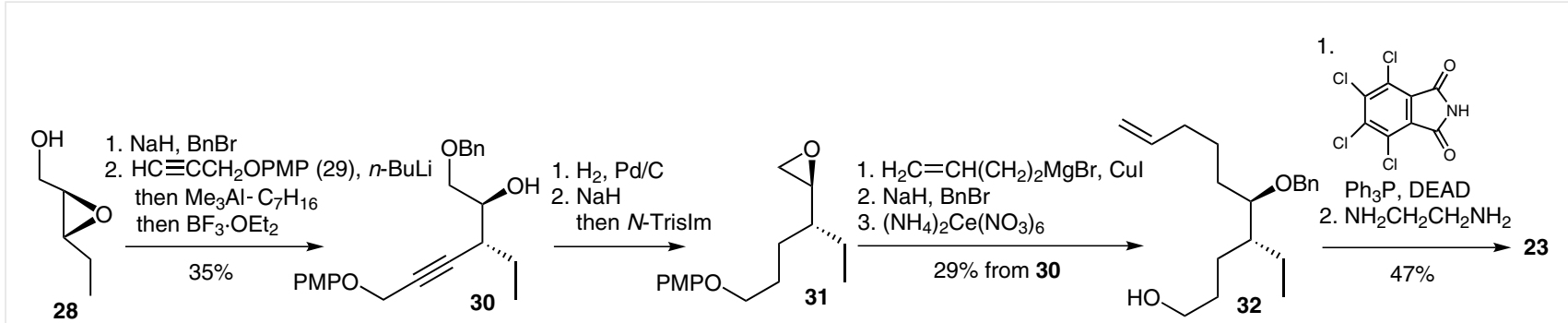

Scheme 7 Preparation of the $C_{5}-N$ fragment in Bracher's synthesis of fluvirucinin $B_{0}$ 


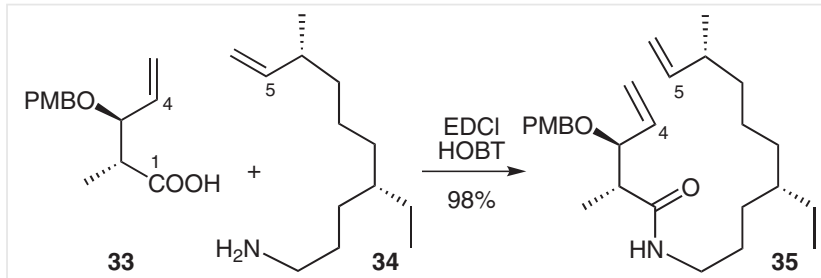

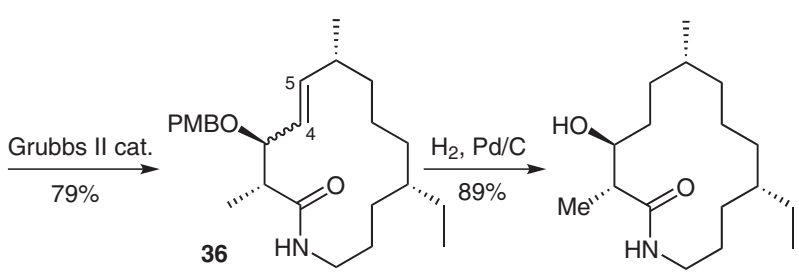

Fluvirucinin $\mathrm{A}_{1}$

Scheme 8 Final steps of Radha Krishna's synthesis of fluvirucinin $A_{1}$

The preparation of amino-alkene 34 started with a highly diastereoselective ( $\mathrm{dr}>$ 95:5) Evans asymmetric alkylation of $N$-butyryloxazolidinone $\mathbf{4 1}$ with the allylic iodide derived from 38, which installed the $\mathrm{C}-10$ stereogenic center of fluvirucinin $A_{1}$ (bond formed $C_{9}-C_{10}$ ). Reductive cleavage of the chiral auxiliary, followed by a two-carbon homologation of the resulting alcohol 43 gave alcohol 44, which was converted into $\mathrm{N}$-Boc-amino alcohol 45. Finally, Swern oxidation and one-carbon Wittig olefination completed the $\mathrm{C}_{5}-\mathrm{N}$ fragment 34 .

\subsubsection{Negishi's Approach to Fluvirucinin $A_{1}$}

An alternative enantioselective synthesis of fluvirucinin $A_{1}$, also using an RCM reaction to promote the macrocyclization, was reported in 2008 by Negishi, ${ }^{19}$ although, unlike other syntheses, in this approach the bond formed was $\mathrm{C}_{8}-\mathrm{C}_{9}$.

The required diene $\mathbf{4 8}$ was prepared in excellent yield by amidation of acid 46 with amine $47\left(C_{1}-C_{8}\right.$ and $C_{9}-N$ fragments of fluvirucinin $A_{1}$ ), and the RCM was performed, also in excellent yield, using Grubbs I catalyst. Subsequent hydrogenation of the olefinic double bond and deprotection afforded fluvirucinin $\mathrm{A}_{1}$ (Scheme 10).

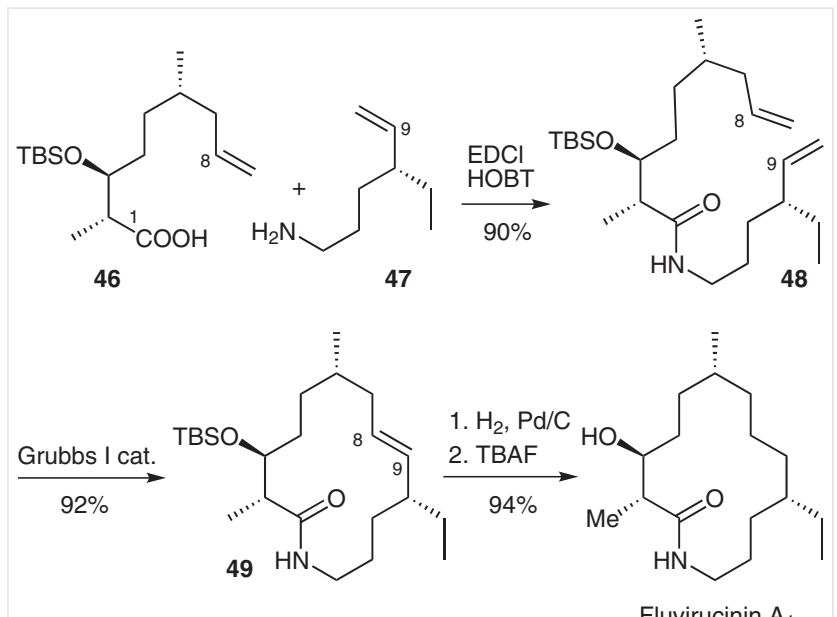

Scheme 10 Final steps of Negishi's synthesis of fluvirucinin $A_{1}$

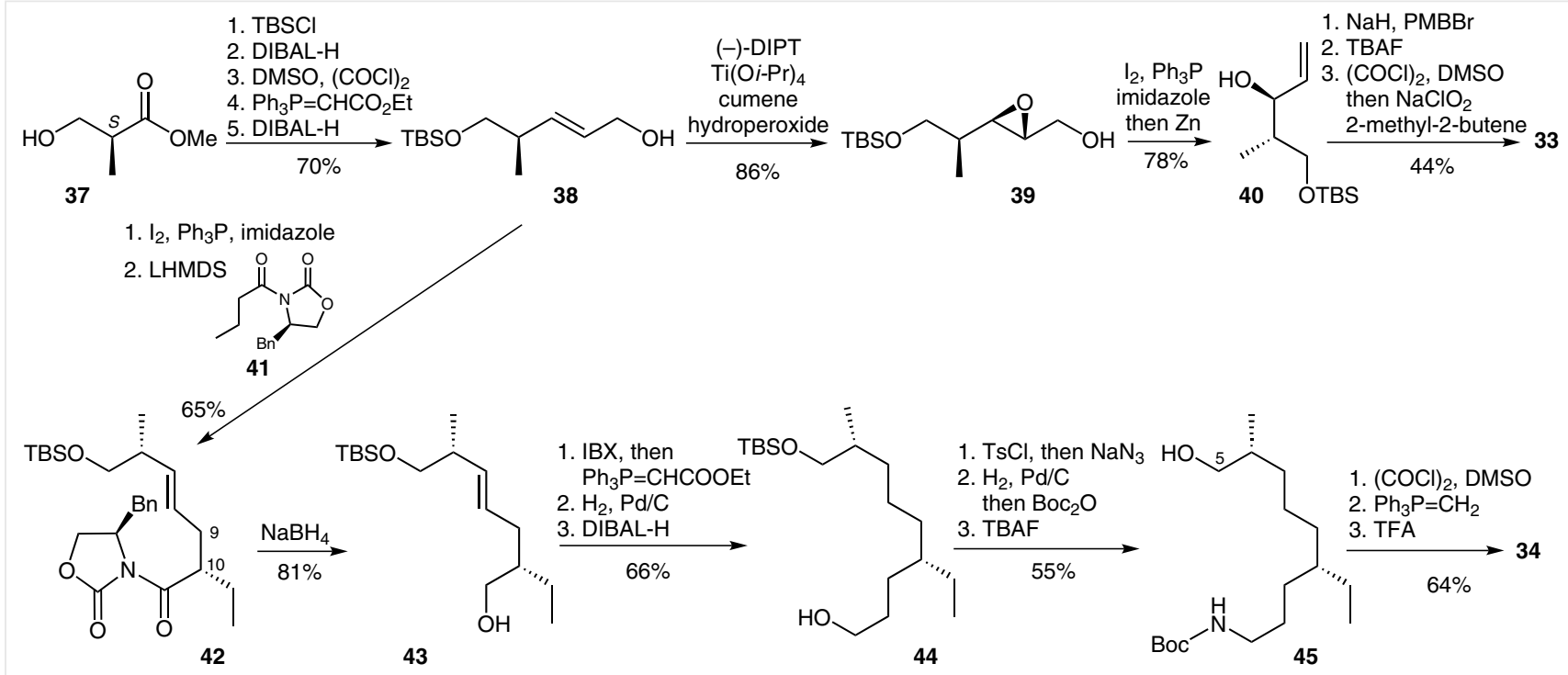

Scheme 9 Preparation of the $C_{1}-C_{4}$ and $C_{5}-N$ fragments in Radha Krishna's synthesis of fluvirucinin $A_{1}$ 

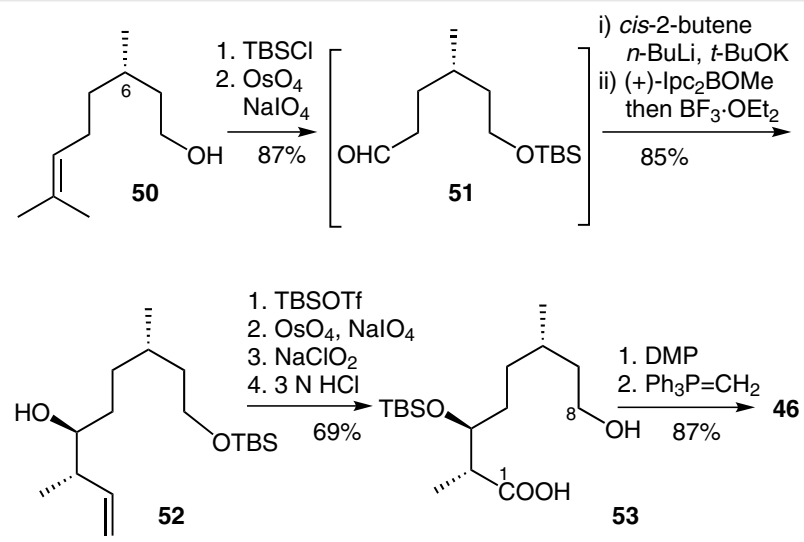

Scheme 11 Preparation of the $C_{1}-C_{8}$ fragment in Negishi's synthesis of fluvirucinin $A_{1}$

$O$-Protected hydroxy acid $\mathbf{4 6}$ was synthesized in nine steps from (-)-(S)- $\beta$-citronellol (50), which provided the C-6 stereogenic center of the target macrocycle. The two other stereocenters of $\mathbf{4 6}$ were stereoselectively ( $\mathrm{dr} \geq 98 \%$ ) generated by Brown crotylboration ${ }^{20}$ of aldehyde $\mathbf{5 1}$, which led to homoallylic alcohol 52 (Scheme 11). The synthesis of the $\mathrm{C}_{1}-\mathrm{C}_{8}$ fragment was completed by oxidative cleavage of the alkene moiety of $\mathbf{5 2}$, protection-deprotection steps, and one-carbon Wittig olefination of the aldehyde resulting from oxidation of alcohol 53.

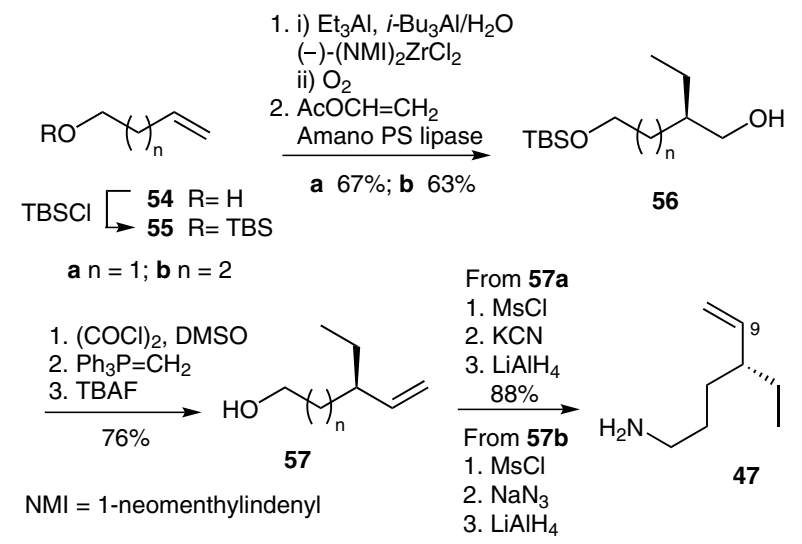

Scheme 12 Preparation of the $\mathrm{C}_{9}-\mathrm{N}$ fragment in Negishi's synthesis of fluvirucinin $A_{1}$

Amino alkene 47 was obtained by two alternative routes, both of them involving a $\mathrm{Zr}$-catalyzed asymmetric carboalumination reaction, followed by purification by lipase-catalyzed acetylation, starting from either 3-buten1-ol (54a) or 4-penten-1-ol (54b). The resulting enantiomerically pure ( $\geq 98 \%$ ee) $(R)$-2-ethyl-1-alkanols $\mathbf{5 6 a}$ and $\mathbf{5 6 b}$, containing the $\mathrm{C}-10$ asymmetric center of fluvirucinin
A, were converted into the $\mathrm{C}_{9}-\mathrm{N}$ fragment $\mathbf{4 7}$ in six conventional steps, via alkenols $\mathbf{5 7}$ a and $\mathbf{5 7 b}$, as shown in Scheme 12.

\subsubsection{The Vilarrasa-Urpi Approach to Fluvirucinin $B_{2-5}$}

In 2009, Vilarrasa and Urpí reported the first, and to date the only, enantioselective synthesis of fluvirucinin $B_{2-5}$, the aglycon common to fluvirucins $B_{2}-B_{5}$, via an RCM reaction involving the formation of the $\mathrm{C}_{6}-\mathrm{C}_{7}$ bond. ${ }^{21}$ The macrocyclization was performed in the presence of the Hoveyda-Grubbs (H-G) II catalyst using diene $\mathbf{6 0}$ as the substrate, which was prepared by direct coupling of carboxylic acid $\mathbf{5 8}$ with azide $\mathbf{5 9}$ using the Staudinger-Vilarrasa reaction (Scheme 13).

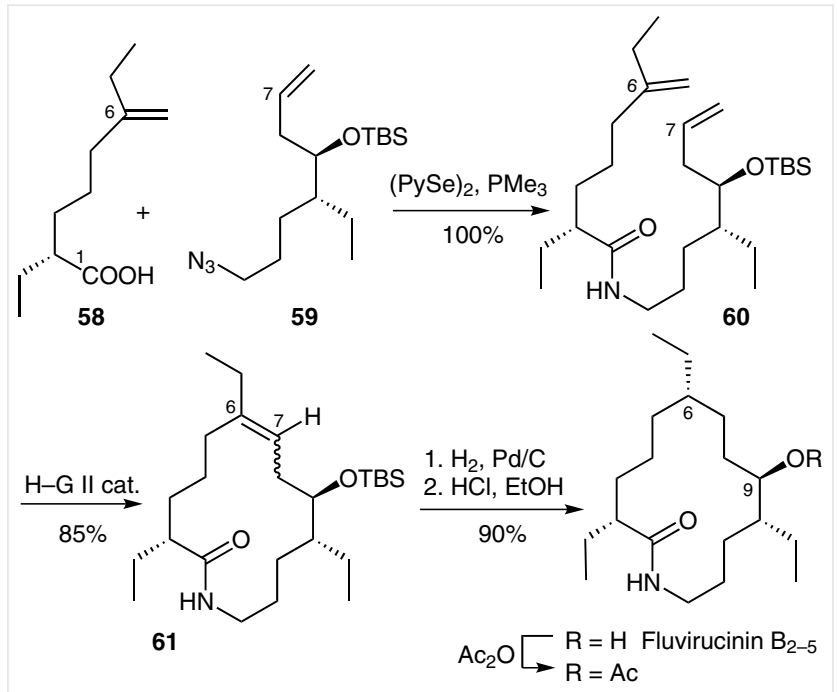

Scheme 13 Final steps of the Vilarrasa-Urpí synthesis of fluvirucinin $\mathrm{B}_{2-5}$

Hydrogenation of the trisubstituted double bond of the resulting unsaturated lactam $\mathbf{6 1}$ (1:1.2 mixture of $Z / E$ isomers) stereoselectively installed the C-6 stereogenic center (9:1 dr); subsequent hydrolysis afforded fluvirucinin $B_{2-5}$. The corresponding acetate was found to be identical to the reported acetylated aglycon derived from fluvirucin $\mathrm{B}_{2}$ (Sch 38518).

Both the ethyl-branched acid $\mathbf{5 8}$ and azide $\mathbf{5 9}$ (the $\mathrm{C}_{1}-\mathrm{C}_{6}$ and $\mathrm{C}_{7}-\mathrm{N}$ fragments of fluvirucinin $\mathrm{B}_{2-5}$ ) were stereoselectively prepared from the same starting material, the known $^{22}$ allylated $\mathrm{N}$-acyloxazolidinone 62 (Scheme 14), which provided the $\mathrm{C}-2$ and $\mathrm{C}-10$ ethyl-substituted stereogenic centers of fluvirucinin $\mathrm{B}_{2-5}$.

Cross-metathesis of $\mathbf{6 2}$ with ethyl vinyl ketone, followed by hydrogenation of the resulting carbon-carbon double bond of enone 63 and selective Petasis ketone methylena- 


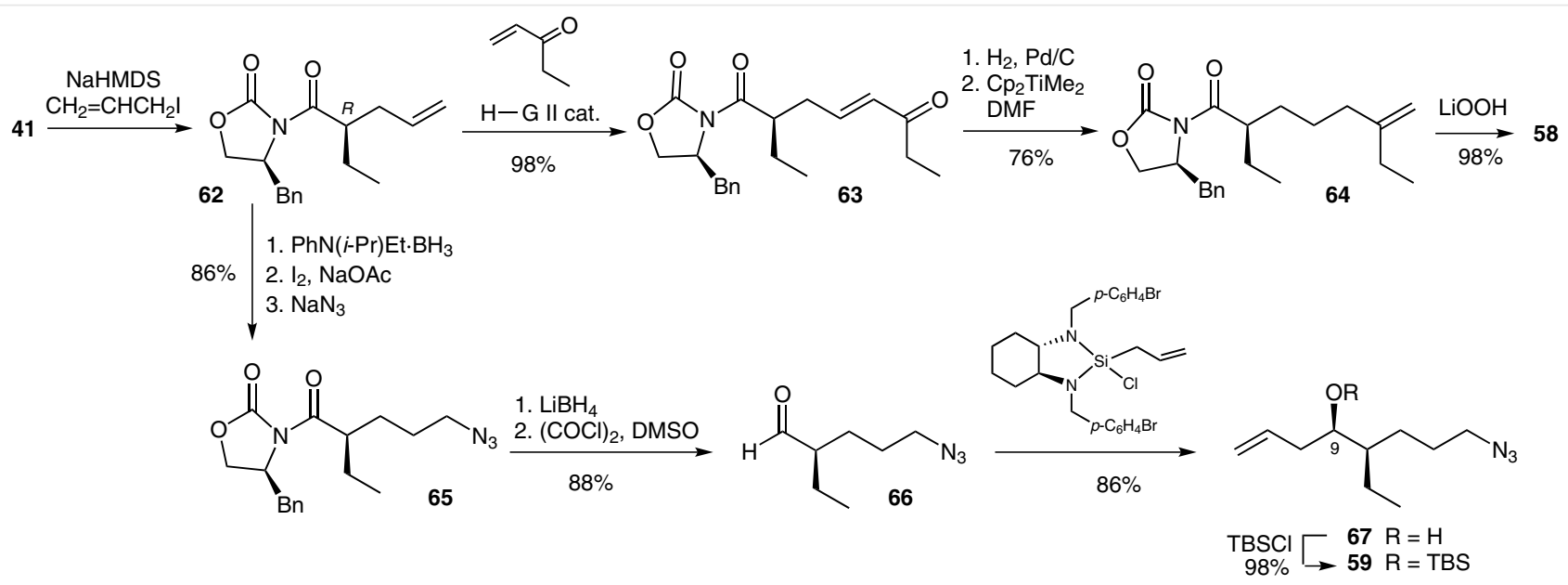

Scheme 14 Preparation of the $C_{1}-C_{6}$ and $C_{7}-N$ fragments in the Vilarrasa-Urpí synthesis of fluvirucinin $B_{2-5}$

tion using DMF as a scavenger, afforded 64. Finally, hydrolytic removal of the chiral auxiliary provided acid $\mathbf{5 8}$ in excellent overall yield.

The conversion of $\mathbf{6 2}$ into azide $\mathbf{5 9}$ commenced with a one-pot hydroboration-iodination process, followed by replacement of the iodine atom by an azide anion. After reductive removal of the auxiliary in $\mathbf{6 5}$ and oxidation of the resulting alcohol, stereoselective $(\mathrm{dr} \geq 98: 2)$ allylation of aldehyde $\mathbf{6 6}$ using the $(S, S)$-Leighton reagent installed the C-9 stereogenic center to give syn alcohol 67, which was protected as its TBS ether.

\subsubsection{The Amat-Bosch Approach to Fluvirucinin $B_{1}$}

Our group has recently disclosed ${ }^{23}$ the enantioselective synthesis of fluvirucinin $\mathrm{B}_{1}$, also employing an RCM reaction to form the strategic $C_{6}-C_{7}$ bond in the key macrocyclization step.

This was accomplished from amido diene 70 (Scheme 15), which was prepared by coupling acid 68 with amine 69 (the $C_{1}-C_{6}$ and $C_{7}-N$ fragments of fluvirucinin $B_{1}$ ). The $C-6$ stereocenter was generated, as in previous syntheses, by stereoselective hydrogenation of the trisubstituted double bond of the macrocyclic alkene 71 (1.2:1 E/Z ratio), leading to the 0 -protected fluvirucinin $\mathrm{B}_{1}$ derivative 72 (absolute configuration unambiguously confirmed by X-ray crystallographic analysis). Finally deprotection gave fluvirucinin $B_{1}$.

A distinctive feature of the synthesis is the use of $(S)$ phenylglycinol-derived amino diol $\mathbf{7 5}$ as the common starting material for the preparation of acid $\mathbf{6 8}$ and amine 69. This amino diol provides the $\mathrm{C}-2$ and $\mathrm{C}-10$ ethyl substituents of the target aglycon, with the required absolute ste-

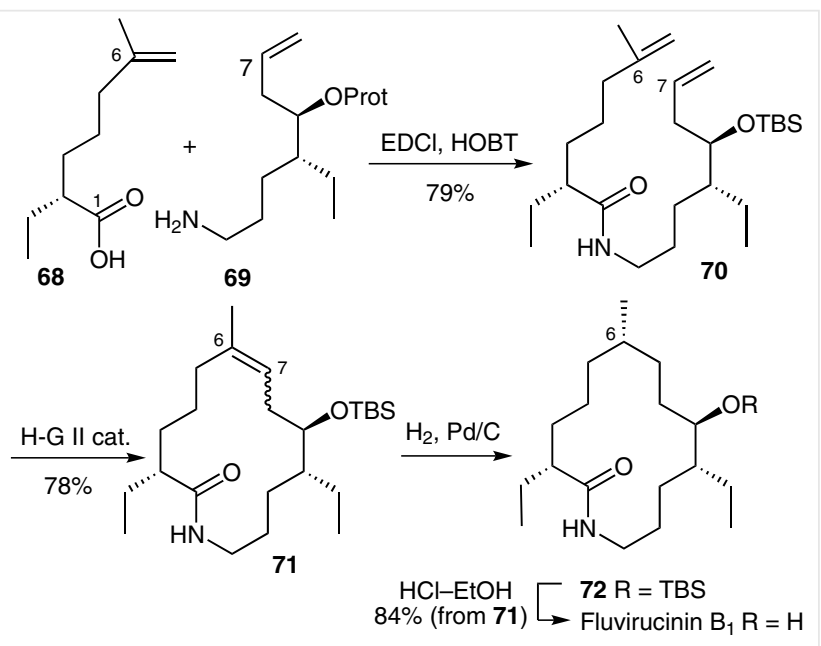

Scheme 15 Final steps of the Amat-Bosch synthesis of fluvirucinin $B_{1}$

reochemistry. It was obtained from oxazolopiperidone lactam 73 by stereoselective alkylation followed by $\mathrm{LiNH}_{2} \cdot \mathrm{BH}_{3}$ reduction of the resulting ethyl-substituted lactam $\mathbf{7 4}$, in a process involving the simultaneous reductive opening of the oxazolidine and lactam rings ${ }^{24}$ (Scheme 16).

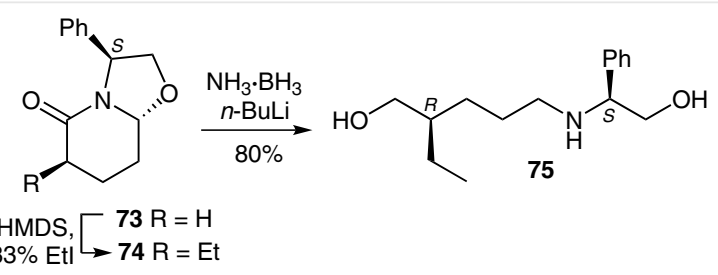

Scheme 16 Preparation of the starting amino diol 75 


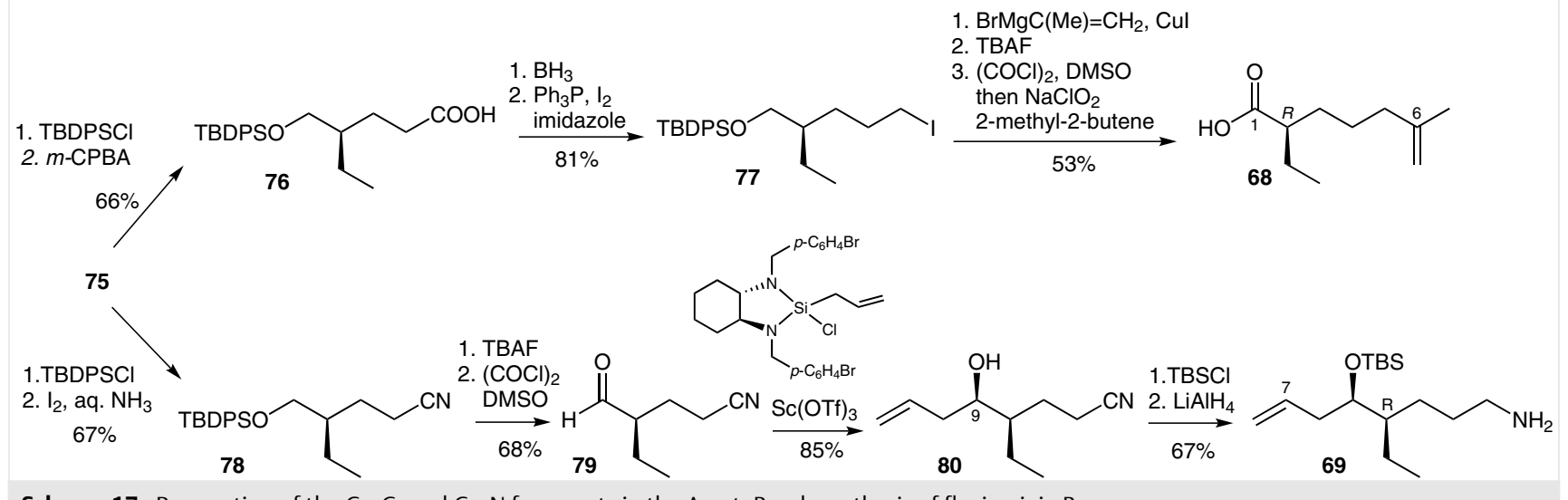

Scheme 17 Preparation of the $C_{1}-C_{6}$ and $C_{7}-N$ fragments in the Amat-Bosch synthesis of fluvirucinin $B_{1}$

After protection of the two hydroxy groups, amino diol $\mathbf{7 5}$ was converted into the $O$-protected hydroxy acid $\mathbf{7 6}$ by an unprecedented $m$-CPBA-promoted transformation involving the regioselective oxidation of a phenylglycinolderived secondary amine to a carboxylic acid. Alternatively, $\mathbf{7 5}$ was converted into nitrile $\mathbf{7 8}$ by $\mathrm{I}_{2} / \mathrm{NH}_{3}$-mediated oxidative cleavage of the secondary amino group (Scheme 17).

The synthesis of the $C_{1}-C_{6}$ fragment $\mathbf{6 8}$ from $\mathbf{7 6}$ was completed, via iodide $\mathbf{7 7}$, by copper-catalyzed cross-coupling reaction with 2-propenylmagnesium bromide, followed by conversion of the alcohol function into a carboxy group. In turn, the $\mathrm{C}_{7}-\mathrm{N}$ fragment $\mathbf{6 9}$ was synthesized from nitrile $\mathbf{7 8}$, via aldehyde $\mathbf{7 9}$, by a diastereoselective Leighton allylation ( $d r=9: 1)$, which introduced the stereogenic center at C-9, and subsequent protection and reduction steps from the resulting alcohol $\mathbf{8 0}$.

\subsection{Closure of the 14-Membered Ring by Macrolac- tamization}

\subsubsection{Trost's Approach to Fluvirucinin $B_{1}$}

In 1997, Trost reported ${ }^{25}$ a synthesis of fluvirucinin $B_{1}$ using a conceptually different approach, in which the macrocyclic ring was assembled by lactamization.

Starting from $\mathrm{N}$-acylimidazolidinone 87, two key intermediates, Meldrum's acid derivative $\mathbf{8 1}$ and epoxide $\mathbf{8 2}\left(C_{1}-C_{5}\right.$ and $\mathrm{C}_{6}-\mathrm{N}$ fragments of fluvirucinin $\mathrm{B}_{1}$ ), were synthesized in enantiopure form. Coupling of these two building blocks (bond formed $\mathrm{C}_{5}-\mathrm{C}_{6}$ ) by palladium-catalyzed addition of the pronucleophile $\mathbf{8 1}$ to alkenyl epoxide $\mathbf{8 2}$ occurred with complete transfer of chirality, via a $\pi$-allylpalladium species, thus creating the proper configuration at C-6. The resulting allylic alcohol 83, which incorporates all stereogenic centers of fluvirucinin $B_{1}$, was obtained as a single diastereomer (Scheme 18). Then, simultaneous hydrogenolysis of<smiles>CC[C@H](CCC1C(=O)OC(C)(C)OC1=O)C(=O)Br</smiles>

81

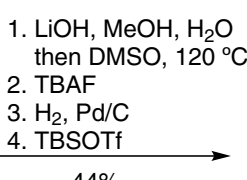

$44 \%$<smiles>C/C=C\C1OC1[C@H](CC)CCCN</smiles>

82<smiles>CCC(C)[C@H](CC)CC[C@@H](CC)C(=O)NCCC[C@@H](CC)C(C)=O</smiles>

85

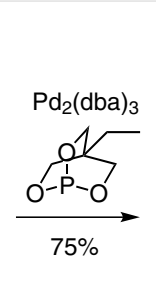

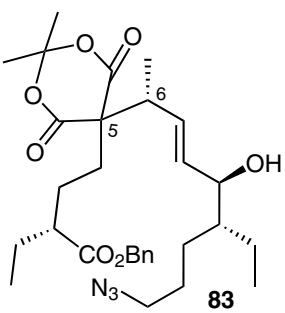

1. TBSOTf

2. $\mathrm{Pd} / \mathrm{C}, \mathrm{HCO}_{2} \mathrm{NH}_{4}, 4 \mathrm{kbar}$ then PyBroP

$\frac{i-\mathrm{Pr}_{2} \mathrm{NEt}, \mathrm{PM}}{39 \%}$<smiles>CCCCCCCNC(=O)[C@H](CC)CC[C@H](C)CCCCC(CC)CC</smiles>

86 O-TBS Fluvirucinin $B_{1}$

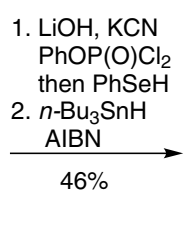<smiles>CCCCNC(=O)[C@@H](CC)CCC1(C(C)/C=C/C(O[Sn])C(CC)CC)C(=O)OC(C)(C)OC1=O</smiles>

86 O-TBS Fluvirucinin $B_{1}$

Scheme 18 Final steps of Trost's synthesis of fluvirucinin $B_{1}$ 


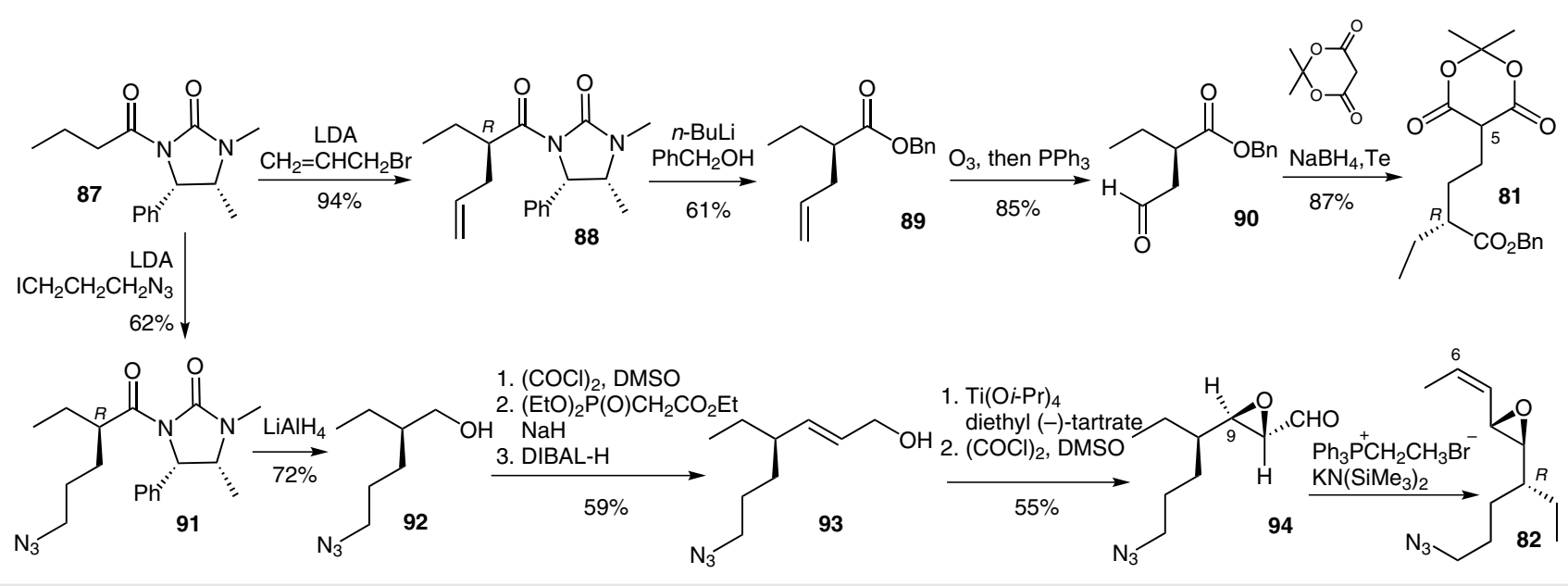

Scheme 19 Preparation of the $C_{1}-C_{5}$ and $C_{6}-N$ fragments in Trost's synthesis of fluvirucinin $B_{1}$

the benzyl ester and azide functionalities and subsequent macrolactamization of the resulting amino acid took place under the reaction conditions depicted in Scheme 18 to give macrolactam 84.

Once the macrocyclic ring system of fluvirucinin $B_{1}$ was assembled, the 1,3-dicarbonyl ester moiety was removed stepwise by base-catalyzed hydrolysis-decarboxylation of $\mathbf{8 4}$ and, after hydrogenation of the olefinic bond, by radical decarbonylation of the acyl phenylselenide derived from ester $\mathbf{8 5}$. The resulting $\mathbf{O}$-silyl derivative $\mathbf{8 6}$ had previously been desilylated to fluvirucinin $B_{1}$.

The synthesis of the key fragments $\mathbf{8 1}$ and $\mathbf{8 2}$ is outlined in Scheme 19. Stereoselective allylation (de $>95 \%$ ) of $\mathrm{N}$-butyrylimidazolidinone $\mathbf{8 7}$, followed by removal of the chiral auxiliary from imidazolidinone $\mathbf{8 8}$, afforded ester $\mathbf{8 9}$. After ozonolysis of the olefinic bond of $\mathbf{8 9}$, the Meldrum's acid moiety was introduced on the resulting aldehyde $\mathbf{9 0}$ by reductive alkylation under Knoevenagel conditions to afford 81.

On the other hand, the synthesis of azide $\mathbf{8 2}$ started with stereoselective alkylation of $\mathbf{8 7}(\geq 95 \%$ de) leading to imidazolidinone 91. Reductive removal of the chiral auxiliary followed by oxidation of the resulting alcohol 92 and a two-carbon homologation-reduction sequence gave allylic alcohol 93. Asymmetric epoxidation afforded a single diastereomeric epoxide, thus defining the C-9 absolute configuration. Subsequent oxidation and a stereoselective Wittig olefination (7:1 $Z / E$ ratio) of the resulting aldehyde $\mathbf{9 4}$ gave the $\mathrm{C}_{6}-\mathrm{N}$ fragment $\mathbf{8 2}$.

\subsubsection{The Vilarrasa-Urpí Approach to Fluvirucinin $\mathrm{B}_{1}$}

In 1999, Vilarrasa and Urpí published ${ }^{26}$ an alternative synthesis of fluvirucinin $\mathrm{B}_{1}$, also involving a lactamization reaction to construct the 14-membered ring. The crucial open-chain precursor $\mathbf{9 8}$ was prepared by stereoselective aldol-like reaction (bond formed $\mathrm{C}_{8}-\mathrm{C}_{9}$ ) between aldehyde 96 and the boron enolate generated from ketone 95 and the menthone-derived boryl bromide $\mathbf{9 7}$ (Scheme 20). Alcohol 98 incorporates all carbon atoms of the target aglycon with the natural configuration in all stereocenters. After the subsequent conversion of syn alcohol 98 (20:1 syn/anti ratio) into $\omega$-azido acid $\mathbf{9 9}$, the macrolactamization to $\mathbf{1 0 0}$ was performed via an $S$-2-pyridyl ester by reduction of the azido group.

A three-step reduction of the ketone carbonyl and deprotection of the alcohol function afforded fluvirucinin $B_{1}$. The spectroscopic data of the corresponding acetate matched those reported in the literature.

Both ketone 95 and aldehyde $96\left(C_{1}-C_{8}\right.$ and $C_{9}-N$ fragments of fluvirucinin $B_{1}$ ) were synthesized from a common intermediate 103, which provided the C-2 and C-10 ethylsubstituted stereocenters of the target aglycon. Compound 103 was accessible in five steps from the known Evans $\mathrm{N}$-acyloxazolidinone $\mathbf{1 0 1}$, via alcohol $102,{ }^{22}$ as outlined in Scheme 21.

The preparation of ketone $\mathbf{9 5}$ featured a diastereoselective alkylation of the $\mathrm{N}$-propanoyl derivative of (-)-pseudoephedrine with the iodide derived from 103, a process that installed the C-6 methyl-substituted stereocenter of fluvirucinin $\mathrm{B}_{1}$. Removal of the chiral auxiliary with MeLi gave methyl ketone $\mathbf{9 5}$. 


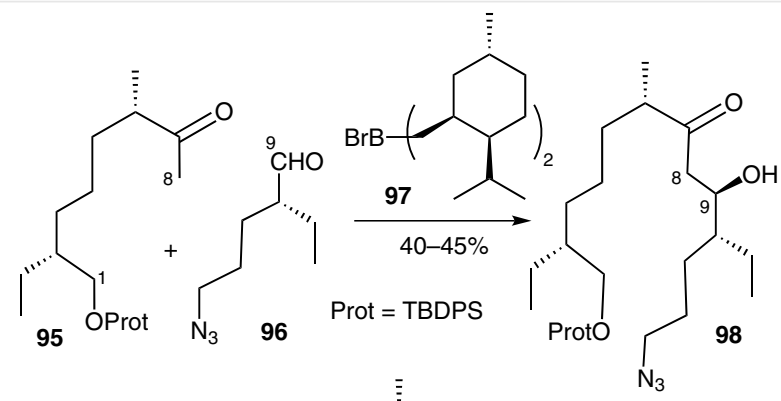

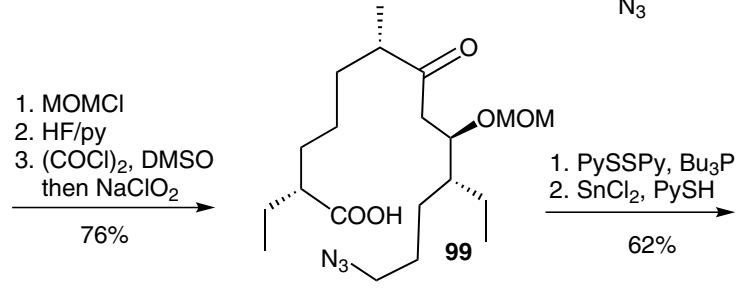

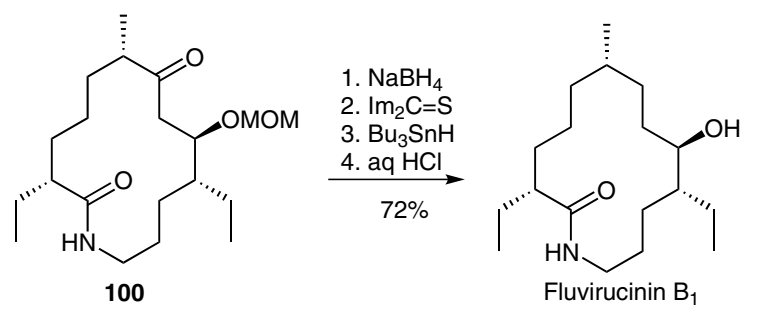

Scheme 20 Final steps of the Vilarrasa-Urpí synthesis of fluvirucinin $B_{1}$

In turn, azido aldehyde 96 was obtained from 103 in three conventional steps: introduction of the azido group, deprotection, and Swern oxidation.

\subsubsection{Suh's Approach to Fluvirucinin $A_{1}$}

The synthesis of fluvirucinin $A_{1}$ by Suh in 1999 was the first synthesis of a member of the fluvirucinin A series. ${ }^{27}$ Before the final lactamization of amino acid 114, the key steps were diastereoselective vinyl addition to a 2-piperidone derivative, amide-enolate aza-Claisen rearrangement to generate the 10 -membered lactam $\mathbf{1 0 9}$, and stereoselec- tive condensation of an aldehyde with the boron enolate of $\mathrm{N}$-propionyloxazolidinone $\mathbf{1 1 2}$.

The synthesis begins with the Evans asymmetric alkylation of $\mathrm{N}$-acyloxazolidinone $\mathbf{1 0 4}$, to install the initial stereogenic center corresponding to $C-10$ of fluvirucinin $A_{1}$, and the conversion of the alkylated product 105 into 2-piperidone 106 (Scheme 22). The corresponding $N$-benzyl derivative was converted into trans-2,3-disubstituted piperidine 107 via a diastereoselective (95:5 trans/cis ratio) vinylation at the lactam carbonyl with the assistance of $\operatorname{LiAl}(\mathrm{OEt})_{3} \mathrm{H}$. Exchange of the benzyl group for propionyl gave amide 108, which underwent stereoselective amide-enolate-induced aza-Claisen rearrangement (bond formed $C_{6}-C_{7}$ ), leading to the ring-expanded lactam 109, which possesses a new stereogenic center, corresponding to $C-6$ of fluvirucinin $A_{1}$. The reaction occurs via a $Z$-enolate in a chair-chair-like transition state bearing an equatorial ethyl substituent.
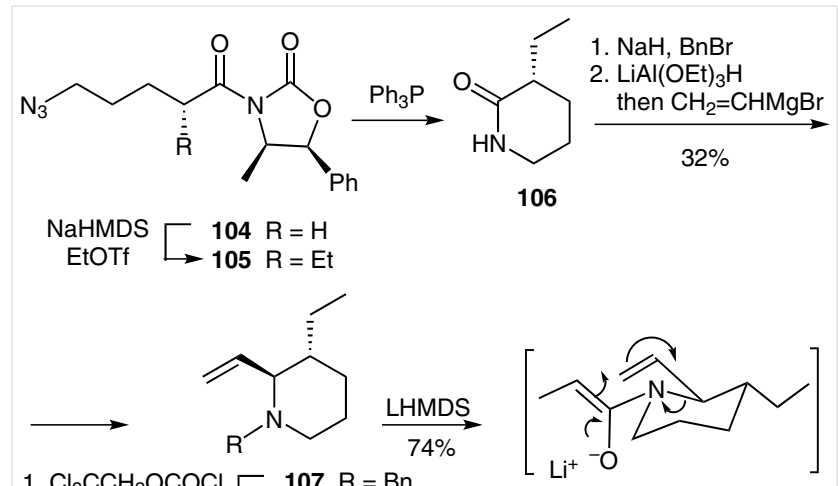

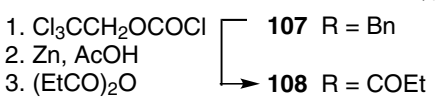

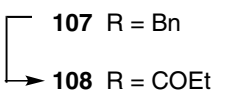

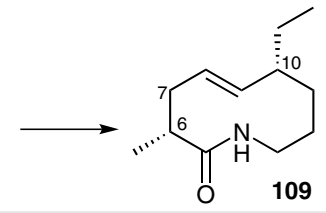
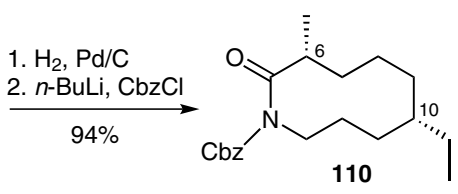

Scheme 22 Initial steps of Suh's synthesis of fluvirucinin $A_{1}$<smiles>CC[C@H](CCC[C@H](C)C(C)=O)COC(=O)C[C@H](CC)CCCN</smiles>

Scheme 21 Preparation of the $C_{1}-C_{8}$ and $C_{9}-N$ fragments in the Vilarrasa-Urpí synthesis of fluvirucinin $B_{1}$ 

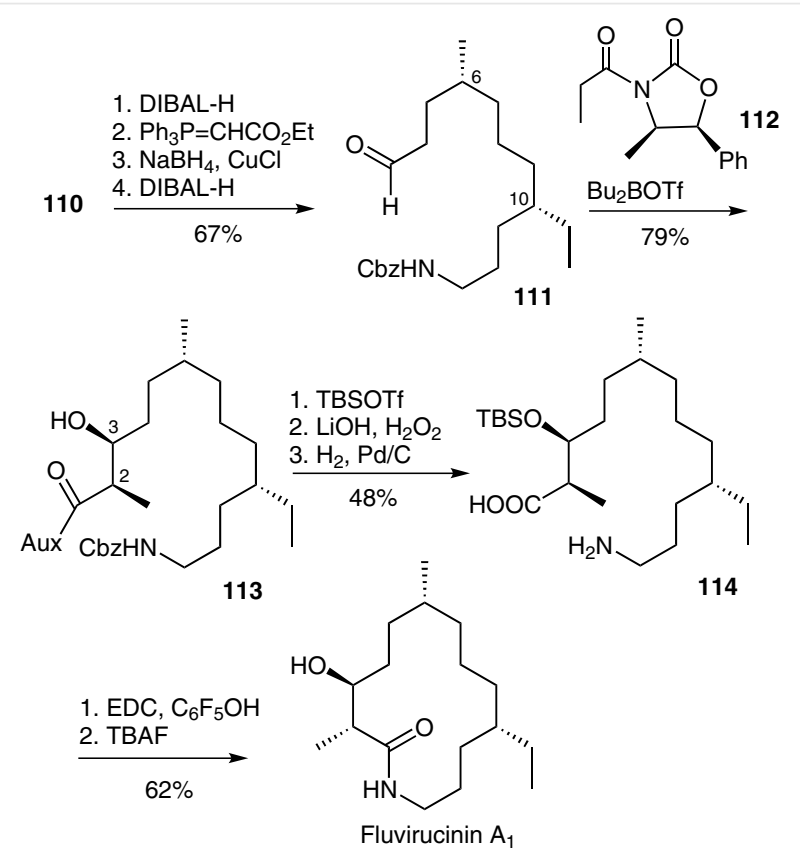

Scheme 23 Final steps of Suh's synthesis of fluvirucinin $A_{1}$

After unsaturated lactam 109 was hydrogenated and Nprotected, reductive ring-opening of lactam 110, followed by a two-carbon Wittig olefination and two reduction steps, afforded saturated aldehyde 111 (Scheme 23). The two remaining stereocenters (C-2 and C-3) were stereoselectively introduced following the Evans protocol by an aldol-type reaction between aldehyde 111 and $N$ propionyloxazolidinone 112. Hydrolytic removal of the auxiliary and protecting-deprotecting steps converted the resulting alcohol 113 into amino acid 114. Subsequent lactamization and deprotection provided synthetic fluvirucinin $A_{1}$, which was identical in all respects to the natural aglycon.

\subsubsection{Fu's Approach to Fluvirucinin $A_{1}$}

In 2008, Fu reported ${ }^{28}$ a formal total synthesis of fluvirucinin $A_{1}$, using two sequential Ni-catalyzed asymmetric $\mathrm{C}\left(\mathrm{sp}^{3}\right)-\mathrm{C}\left(\mathrm{sp}^{3}\right)$ Negishi cross-coupling reactions of allylic chlorides as the key steps.

The synthesis started from ethyl (E)-4-oxo-2-butenoate, which was converted in two steps into racemic secondary allylic chloride 116a (Scheme 24).

Nickel(II)-catalyzed cross-coupling of 116a with alkylzinc reagent 115 in the presence of Pybox ligand 117 provided compound 118 in excellent yield and almost complete regio- (>20:1) and enantioselectivity (96\% ee). Compound 118 was converted into bromide 119 and then into the corresponding alkylzinc derivative, which was subject-

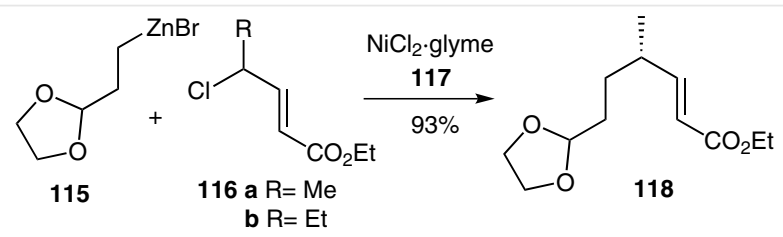<smiles>CCOC(=O)/C=C\[C@H](CC)CCC[C@@H](C)CCC1OCCO1</smiles><smiles>CC[C@@H](CCCNC(=O)O)CCC[C@H](C)CCC(=O)NC(=O)OCc1ccccc1</smiles>

Scheme 24 Fu's formal synthesis of fluvirucinin $A_{1}$

ed to a second nickel(II)-catalyzed asymmetric crosscoupling reaction with racemic allylic chloride $\mathbf{1 1 6 b}$ to generate unsaturated ester $\mathbf{1 2 0}$ in excellent diastereo- (15:1 ratio) and enantioselectivity ( $>98 \%$ ee). A subsequent reduction-amination sequence provided $\mathrm{N}$-protected amino aldehyde 111, an advanced intermediate in Suh's synthesis of fluvirucinin $A_{1}$.

\subsection{Construction of the 14-Membered Ring by Aza- Claisen Ring Expansion}

\subsubsection{Suh's Approach to Fluvirucinin $A_{2}$}

In 2010, Suh contributed ${ }^{29}$ the first total synthesis of fluvirucinin $A_{2}$ by iterative lactam ring expansion via an amide-enolate-induced aza-Claisen rearrangement that provided the 14-membered lactam skeleton with the required absolute configuration at all ring stereogenic centers.

The 10-membered lactam 109, an early intermediate in Suh's synthesis of fluvirucinin $A_{1}$, prepared by an initial amide-enolate-induced aza-Claisen rearrangement, ${ }^{27}$ was converted into $\mathrm{N}$-Boc saturated lactam 121 (Scheme 25). After partial reduction of the lactam carbonyl and trapping of the resulting $\mathrm{N}, \mathrm{O}$-hemiacetal as a silyl ether, stereoselective amidoalkylation led to allyl azacycle $\mathbf{1 2 2}$, which was protected as the Fmoc derivative 123. Oxidative cleavage of the allyl group to an aldehyde, followed by silylation stereoselectively afforded the required (E)-silyl enol ether $\mathbf{1 2 4}$ $(E \mid Z>10: 1)$. 

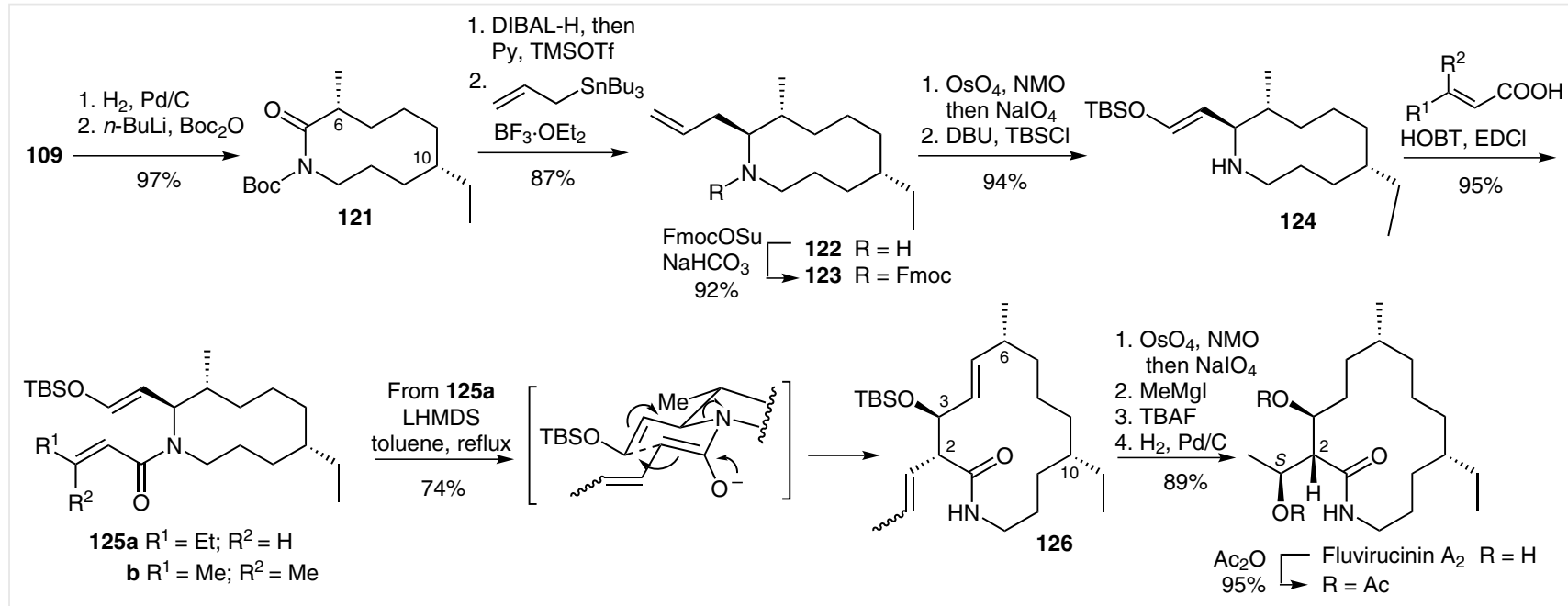

Scheme 25 Suh's synthesis of fluvirucinin $A_{2}$

The corresponding (E)-2-pentenamide 125a underwent regio- and stereoselective ( $\mathrm{dr}>10: 1)$ vinylogous amideenolate-induced aza-Claisen rearrangement, via a highly favorable transition state, leading to lactam 126 (bond formed $\mathrm{C}_{2}-\mathrm{C}_{3}$ ), with generation of the $\mathrm{C}-2$ and $\mathrm{C}-3$ stereogenic centers. Selective oxidation of the propenyl appendage of 126, followed by a stereoselective Grignard addition to the resulting aldehyde, left the (S)-1-hydroxyethyl chain at C-2. Deprotection of the C-3 hydroxy group and hydrogenation of the olefinic double bond completed the synthesis of fluvirucinin $A_{2}$, whose diacetate exhibited spectral data identical to those of the diacetate derived from the natural aglycon.

The stereoselectivity of the aza-Claisen rearrangement was dependent on the substitution at the unsaturated $\mathrm{N}$-acyl moiety. Thus, when starting from $\mathrm{N}$-(3,3-dimethylacryloyl) derivative $\mathbf{1 2 5 b}$, the rearrangement was not stereoselective, leading to a 1:1 mixture of macrolactam $\mathbf{1 2 7}$ and its C-2 epimer, probably due to a nonselective formation of the Z-enolate (Scheme 26).

Compound 127 was converted into epi-fluvirucinin $A_{2}$ by manipulation of the isopropenyl chain at C-2 and subsequent deprotection and hydrogenation steps. The $R$ configuration of the 1-hydroxyethyl moiety was attained by stereoselective $\mathrm{NaBH}_{4}$ reduction of a ketone generated by selective oxidative cleavage of the isopropenyl double bond.

The structures of the synthetic fluvirucinin $A_{2}$ and its epi-derivative were confirmed by an alternative synthesis of epi-fluvirucinin $A_{2}$ employing a Baeyer-Villiger oxidation to ensure the $R$ configuration of the 1-hydroxyethyl chain.

After acylation of the 10-membered amine intermediate 122 with the $R$-configurated mixed anhydride 128 and conversion of the allyl chain into an (E)-silyl enol ether, treatment of $\mathbf{1 2 9}$ under aza-Claisen rearrangement conditions afforded the 14-membered lactam 130 (Scheme 27). The $(R)$-benzyloxymethyl substituent in the $\mathrm{C}-2$ chain of
130 was converted into $(R)$-acetyl in $\mathbf{1 3 1}$ and then to $(R)$ acetoxy in 132, via a Baeyer-Villiger oxidation with retention of configuration.

The spectral data of epi-fluvirucinin $A_{2}$ prepared by this approach were identical to those of epi-fluvirucinin $A_{2}$ synthesized by the route depicted in Scheme 26 .

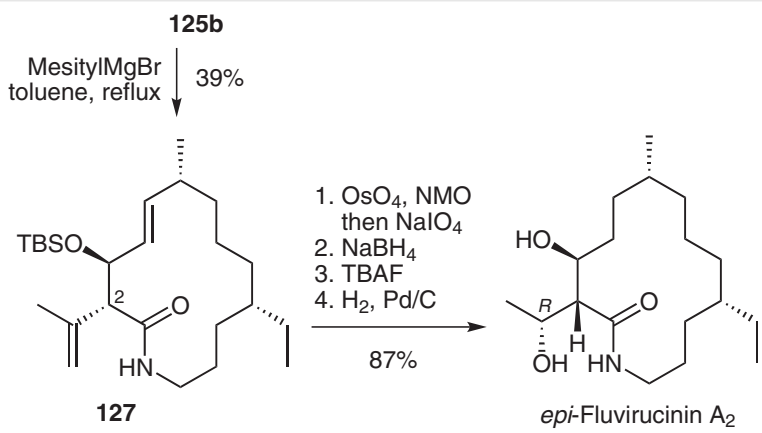

Scheme 26 Suh's synthesis of epi-fluvirucinin $\mathrm{A}_{2}$

\subsubsection{The Suh-Jung Stereocontrolled Approach to Fluvirucinin $A_{1}$ and Its C-3 Epimer}

In the context of a systematic investigation of the azaClaisen rearrangement induced ring expansion of azacycles and its stereochemical outcome, in 2012 Suh and Jung reported $^{30}$ an alternative synthesis of fluvirucinin $A_{1}$. Based on a stereoselective $(E)$ - and $(Z)$-silyl enol ether formation and subsequent ring expansion of the resulting 10-membered 1-acyl-2-alkoxyvinyl azacycles, it provides stereocontrolled access to both fluvirucinin $\mathrm{A}_{1}$ and its $\mathrm{C}-3$ epimer.

The starting allyl azacycle $\mathbf{1 3 3}$ was stereoselectively prepared by the procedure outlined in Scheme 25 , by amidoalkylation of the corresponding lactam. ${ }^{29}$ Ozonolysis of 133 gave aldehyde 134, which was then converted with al- 
<smiles>C=CC[C@H](C)[C@H](C)CCCCCCCC</smiles>

1.<smiles>C[C@H](COc1ccccc1)CC(=O)OC(=O)C(C)(C)C</smiles>

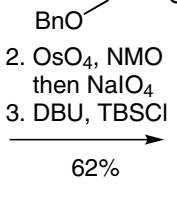
28 TBSO<smiles>COc1ccccc1Br</smiles><smiles>C/C=C\[C@H]1[C@@H](C)CCC[C@@H](CC)CCCN1C(=O)CC</smiles>

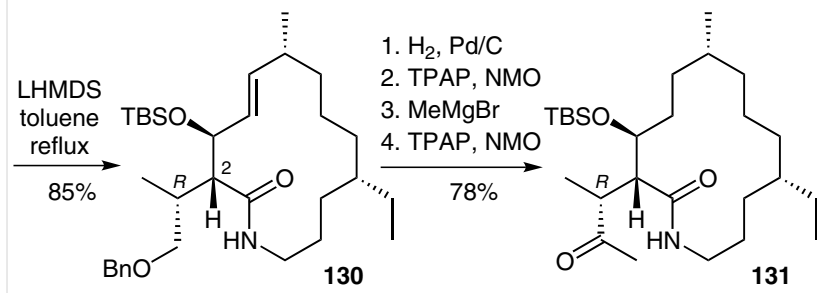
131

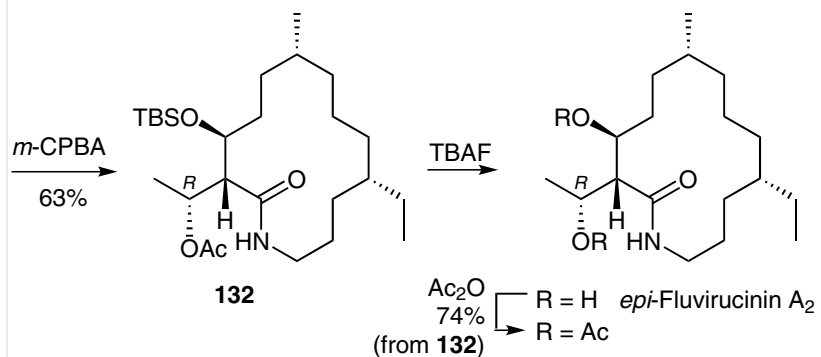

Scheme 27 Alternative synthesis of epi-fluvirucinin $A_{2}$

most complete stereoselectivity into either the $(E)$-silyl enol ether $E$-135 or the $Z$-isomer Z-135, depending on the reaction conditions (Scheme 28 ).

These silyl enol ethers underwent a stereospecific amide-enolate-induced aza-Claisen rearrangement (bond formed $\mathrm{C}_{2}-\mathrm{C}_{3}$ ), via the chair-like transition states depicted in Scheme 28, providing the respective C-3 isomeric 14- membered lactams 136 and 3-epi-136, which were then converted into fluvirucinin $\mathrm{A}_{1}$ and its $\mathrm{C}-3$ epimer.

\section{Conclusion}

Considerable work remains to be done on the synthesis of fluvirucins. To date, the only member of this family of natural products to have been synthesized is fluvirucin $B_{1}$, which incorporates 3-amino-3,6-dideoxy- $\alpha$-L-talopyranose as the aminosugar moiety. No syntheses of fluvirucins bearing L-mycosamine as the carbohydrate fragment have been reported.

In contrast, the synthesis of fluvirucinins has attracted considerable attention and a variety of strategies and procedures have been employed to assemble the macrocyclic ring system. Table 1 summarizes the synthetic strategies used for the construction of the 14-membered ring of fluvirucinins, showing the bond formed in the macrocyclization step in each case. Except when the 14-membered ring is assembled by expansion of a 10 -membered ring, the table also indicates the bond formed to complete the openchain skeleton before the macrocyclization step, as well as the length of the two fragments used and the ring atoms they incorporate.

All the reported syntheses are enantioselective and most of them highly convergent, in many cases accessing both key intermediates from a single enantiopure building block. By an appropriate selection of the starting materials, many of the strategies developed could be applied to the synthesis of other members of the fluvirucinin family.

Finally, it should be noted that the synthetic activity in this area has stimulated the development and extensive application of new synthetic methodologies such as RCM macrocyclizations, as well as the use of metal-catalyzed transformations in crucial synthetic steps.

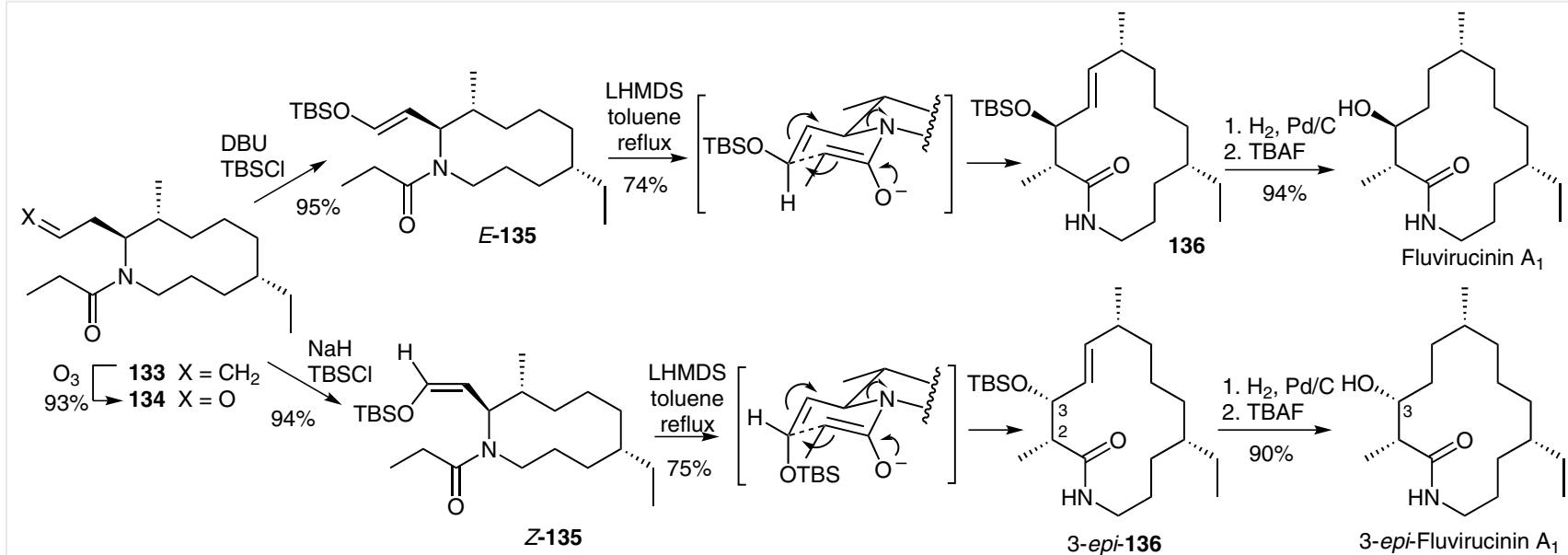

Scheme 28 The Suh-Jung synthesis of fluvirucinin $A_{1}$ and 3-epi-fluvirucinin $A_{1}$ 
Table 1 Summary of Synthetic Strategies

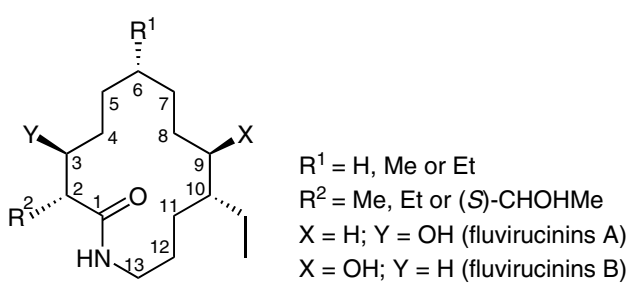

\begin{tabular}{|c|c|c|c|}
\hline Authors (Year) & $\begin{array}{l}\text { Bond formed in the construction of } \\
\text { the } 14 \text {-membered ring }\end{array}$ & $\begin{array}{l}\text { Bond formed and fragments used to com- } \\
\text { plete the open-chain skeleton }\end{array}$ & Final target \\
\hline Hoveyda $^{10-12}(1995,1996,1997)$ & $\mathrm{C}_{5}-\mathrm{C}_{6}$ & $C_{1}-N: 5 C\left(C_{1}-C_{5}\right)+8 C\left(C_{6}-N\right)$ & Fluvirucinin $\mathrm{B}_{1}$; Fluvirucin $\mathrm{B}_{1}$ \\
\hline Bracher $^{14}(2002)$ & $C_{4}-C_{5}$ & $C_{1}-N: 4 C\left(C_{1}-C_{4}\right)+9 C\left(C_{5}-N\right)$ & Fluvirucinin $\mathrm{B}_{0}$ \\
\hline Radha Krishna ${ }^{17}$ (2011) & $\mathrm{C}_{4}-\mathrm{C}_{5}$ & $\mathrm{C}_{1}-\mathrm{N}: 4 \mathrm{C}\left(\mathrm{C}_{1}-\mathrm{C}_{4}\right)+9 \mathrm{C}\left(\mathrm{C}_{6}-\mathrm{N}\right)$ & Fluvirucinin $A_{1}$ \\
\hline Negishi ${ }^{19}(2008)$ & $\mathrm{C}_{8}-\mathrm{C}_{9}$ & $\mathrm{C}_{1}-\mathrm{N}: 8 \mathrm{C}\left(\mathrm{C}_{1}-\mathrm{C}_{8}\right)+5 \mathrm{C}\left(\mathrm{C}_{9}-\mathrm{N}\right)$ & Fluvirucinin $A_{1}$ \\
\hline Vilarrasa-Urpí ${ }^{21}$ (2009) & $\mathrm{C}_{6}-\mathrm{C}_{7}$ & $\mathrm{C}_{1}-\mathrm{N}: 6 \mathrm{C}\left(\mathrm{C}_{1}-\mathrm{C}_{6}\right)+7 \mathrm{C}\left(\mathrm{C}_{7}-\mathrm{N}\right)$ & Fluvirucinin $B_{2-5}$ \\
\hline Amat-Bosch ${ }^{23}$ (2016) & $C_{6}-C_{7}$ & $C_{1}-N: 6 C\left(C_{1}-C_{6}\right)+7 C\left(C_{7}-N\right)$ & Fluvirucinin $\mathrm{B}_{1}$ \\
\hline Trost $^{25}(1997)$ & $\mathrm{C}_{1}-\mathrm{N}$ & $C_{5}-C_{6}: 5 C\left(C_{1}-C_{5}\right)+8 C\left(C_{6}-N\right)$ & Fluvirucinin $\mathrm{B}_{1}$ \\
\hline Vilarrasa-Urpíi ${ }^{26}$ (1999) & $\mathrm{C}_{1}-\mathrm{N}$ & $\mathrm{C}_{8}-\mathrm{C}_{9}: 8 \mathrm{C}\left(\mathrm{C}_{1}-\mathrm{C}_{8}\right)+5 \mathrm{C}\left(\mathrm{C}_{9}-\mathrm{N}\right)$ & Fluvirucinin $\mathrm{B}_{1}$ \\
\hline $\operatorname{Suh}^{27}$ (1999); Fu ${ }^{28}$ (2008, formal) & $\mathrm{C}_{1}-\mathrm{N}$ & $C_{2}-C_{3}: 2 C\left(C_{1}-C_{2}\right)+11 C\left(C_{3}-N\right)$ & Fluvirucinin $A_{1}$ \\
\hline $\operatorname{Suh}^{29}(2010)$ & $\mathrm{C}_{2}-\mathrm{C}_{3}$ & 10-membered ring expansion & Fluvirucinin $\mathrm{A}_{2}$ \\
\hline Suh-Jung ${ }^{30}(2012)$ & $\mathrm{C}_{2}-\mathrm{C}_{3}$ & 10-membered ring expansion & Fluvirucinin $A_{1}$ \\
\hline
\end{tabular}

\section{Acknowledgment}

Work in the authors' laboratory was supported by the MINECO/FEDER, Spain (projects CTQ2012-35250 and CTQ2015-65384-R) and the AGAUR, Generalitat de Catalunya (Grant 2014-SGR-155). We also acknowledge the networking contribution from the COST Action CM1407.

\section{References}

(1) Hegde, V. R.; Patel, M. G.; Gullo, V. P.; Ganguly, A. K.; Sarre, O.; Puar, M. S.; McPhail, A. T. J. Am. Chem. Soc. 1990, 112, 6403.

(2) (a) Hegde, V. R.; Patel, M. G.; Gullo, V. P.; Puar, M. S. J. Chem. Soc., Chem. Commun. 1991, 810. (b) Hegde, V.; Patel, M.; Horan, A.; Gullo, V.; Marquez, J.; Gunnarsson, I.; Gentile, F.; Loebenberg, D.; King, A.; Puar, M.; Pramanik, B. J. Antibiot. 1992, 45, 624. (c) Cooper, R.; Truumees, I.; Yarborough, R.; Loebenberg, D.; Marquez, J.; Horan, A.; Patel, M.; Gullo, V.; Puar, M.; Pramanik, B. J. Antibiot. 1992, 45, 633.

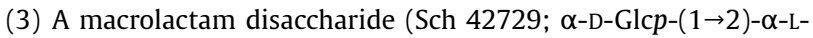
mycosamine $)^{3 a}$ and a macrolactam trisaccharide (Sch $42282 ; \beta-$ D-Glcp- $(1 \rightarrow 4)-\alpha-D-G l c p-(1 \rightarrow 2)-\alpha$-L-mycosamine $)^{3 \mathrm{~b}}$ bearing the same aglycon as Sch 38518 were also isolated: (a) Hegde, V. R.; Patel, M. G.; Gullo, V. P.; Horan, A. C.; King, A. H.; Gentile, F.; Wagman, G. H.; Puar, M. S.; Loebenberg, D. J. Antibiot. 1993, 46, 1109. (b) Hegde, V. R.; Patel, M. G.; Horan, A. C.; King, A. H.; Gentile, F.; Puar, M. S.; Loebenberg, D. J. Antibiot. 1998, 51, 464.
(4) (a) Naruse, N.; Tenmyo, O.; Kawano, K.; Tomita, K.; Ohgusa, N.; Miyaki, T.; Konishi, M.; Oki, T. J. Antibiot. 1991, 44, 733. (b) Naruse, N.; Tsuno, T.; Sawqada, Y.; Konishi, M.; Oki, T. J. Antibiot. 1991, 44, 741. (c) Naruse, N.; Konishi, M.; Oki, T.; Inouye, Y.; Kakisawa, H. J. Antibiot. 1991, 44, 756.

(5) Ui, H.; Imoto, M.; Umezawa, K. J. Antibiot. 1995, 48, 387.

(6) Ayers, S.; Zink, D. L.; Powell, J. S.; Brown, C. M.; Grund, A.; Genilloud, O.; Salazar, O.; Thompson, D.; Singh, S. B. J. Antibiot. 2008, 61, 59.

(7) Ayers, S.; Zink, D. L.; Mohn, K.; Powell, J. S.; Brown, C. M.; Murphy, T.; Grund, A.; Genilloud, O.; Salazar, O.; Thompson, D.; Singh, S. B. J. Nat. Prod. 2007, 70, 1371.

(8) Puar, M. S.; Gullo, V.; Gunnarsson, I.; Hegde, V.; Patel, M.; Schwartz, J. Bioorg. Med. Chem. Lett. 1992, 2, 575.

(9) Lin, T.-Y.; Borketey, L. S.; Prasad, G.; Waters, S. A.; Schnarr, N. A. ACS Synth. Biol. 2013, 2, 635.

(10) Houri, A. F.; Xu, Z.; Cogan, D. A.; Hoveyda, A. H. J. Am. Chem. Soc. 1995, 117, 2943.

(11) Xu, Z.; Johannes, C. W.; Houri, A. F.; La, D. S.; Cogan, D. A.; Hofilena, G. E.; Hoveyda, A. H. J. Am. Chem. Soc. 1997, 119, 10302.

(12) Xu, Z.; Johannes, C. W.; Salman, S. S.; Hoveyda, A. H. J. Am. Chem. Soc. 1996, 118, 10926.

(13) Xu, Z.; Johannes, C. W.; La, D. S.; Hofilena, G. E.; Hoveyda, A. H. Tetrahedron 1997, 53, 16377.

(14) Baltrusch, A. W.; Bracher, F. Synlett 2002, 1724.

(15) (a) Vandewalle, M.; Van der Eycken, J.; Oppolzer, W.; Vullioud, C. Tetrahedron 1986, 42, 4035. (b) Thom, C.; Kocieński, P. Synthesis 1992, 582.

(16) Honda, M.; Katsuki, T.; Yamaguchi, M. Tetrahedron Lett. 1984, $25,3857$.

(17) Radha Krishna, P.; Anitha, K. Tetrahedron Lett. 2011, 52, 4546. 
(18) (a) Mendlik, M. T.; Cottard, M.; Rein, T.; Helquist, P. Tetrahedron Lett. 1997, 38, 6375. (b) Fürstner, A.; Bouchez, L. C.; Funel, J.-A.; Liepins, V.; Porée, F.-H.; Gilmour, R.; Beaufils, F.; Laurich, D.; Tamiya, M. Angew. Chem. Int. Ed. 2007, 46, 9265.

(19) Liang, B.; Negishi, E. Org. Lett. 2008, 10, 193.

(20) Brown, H. C.; Bhat, K. S. J. Am. Chem. Soc. 1986, 108, 5919.

(21) Llàcer, E.; Urpí, F.; Vilarrasa, J. Org. Lett. 2009, 11, 3198.

(22) Evans, D. A.; Rieger, D. L.; Jones, T. K.; Kaldor, S. W. J. Org. Chem. 1990, 55, 6260.

(23) Guignard, G.; Llor, N.; Molins, E.; Bosch, J.; Amat, M. Org. Lett. 2016, 18, 1788.

(24) Guignard, G.; Llor, N.; Bosch, J.; Amat, M. Eur. J. Org. Chem. 2016, 693.
(25) Trost, B. M.; Ceschi, M. A.; König, B. Angew. Chem., Int. Ed. Engl. 1997, 36, 1486.

(26) Martín, M.; Mas, G.; Urpí, F.; Vilarrasa, J. Angew. Chem. Int. Ed. 1999, 38, 3086.

(27) Suh, Y.-G.; Kim, S.-A.; Jung, J.-K.; Shin, D.-Y.; Min, K.-H.; Koo, B.A.; Kim, H.-S. Angew. Chem. Int. Ed. 1999, 38, 3545.

(28) Son, S.; Fu, G. C. J. Am. Chem. Soc. 2008, 130, 2756.

(29) Lee, Y.-S.; Jung, J.-W.; Kim, S.-H.; Jung, J.-K.; Paek, S.-M.; Kim, N.J.; Chang, D.-J.; Lee, J.; Suh, Y.-G. Org. Lett. 2010, 12, 2040.

(30) Suh, Y.-G.; Lee, Y.-S.; Kim, S.-H.; Jung, J.-K.; Yun, H.; Jang, J.; Kim, N.-J.; Jung, J.-W. Org. Biomol. Chem. 2012, 10, 561. 